\title{
Suitability of 3D human brain spheroid models to distinguish toxic effects of gold and poly-lactic acid nanoparticles to assess biocompatibility for brain drug delivery
}

Paulo Emílio Corrêa Leite ${ }^{1 * \dagger}$, Mariana Rodrigues Pereira ${ }^{2 \dagger}$, Georgina Harris ${ }^{3+}$, David Pamies ${ }^{3,7}$, Lisia Maria Gobbo dos Santos ${ }^{4}$, José Mauro Granjeiro ${ }^{1,6}$, Helena T. Hogberg ${ }^{3}$, Thomas Hartung ${ }^{3,5}$ and Lena Smirnova ${ }^{3 *}$ (1)

\begin{abstract}
Background: The blood brain barrier (BBB) is the bottleneck of brain-targeted drug development. Due to their physico-chemical properties, nanoparticles (NP) can cross the BBB and accumulate in different areas of the central nervous system (CNS), thus are potential tools to carry drugs and treat brain disorders. In vitro systems and animal models have demonstrated that some NP types promote neurotoxic effects such as neuroinflammation and neurodegeneration in the CNS. Thus, risk assessment of the NP is required, but current $2 \mathrm{D}$ cell cultures fail to mimic complex in vivo cellular interactions, while animal models do not necessarily reflect human effects due to physiological and species differences.

Results: We evaluated the suitability of in vitro models that mimic the human CNS physiology, studying the effects of metallic gold NP (AuNP) functionalized with sodium citrate (Au-SC), or polyethylene glycol (Au-PEG), and polymeric polylactic acid NP (PLA-NP). Two different 3D neural models were used (i) human dopaminergic neurons differentiated from the LUHMES cell line (3D LUHMES) and (ii) human iPSC-derived brain spheroids (BrainSpheres). We evaluated NP uptake, mitochondrial membrane potential, viability, morphology, secretion of cytokines, chemokines and growth factors, and expression of genes related to ROS regulation after 24 and $72 \mathrm{~h}$ exposures. NP were efficiently taken up by spheroids, especially when PEGylated and in presence of glia. AuNP, especially PEGylated AuNP, effected mitochondria and anti-oxidative defense. PLA-NP were slightly cytotoxic to 3D LUHMES with no effects to BrainSpheres.
\end{abstract}

Conclusions: 3D brain models, both monocellular and multicellular are useful in studying NP neurotoxicity and can help identify how specific cell types of CNS are affected by NP.

Keywords: Nanoparticle, Drug delivery, CNS, iPSC-derived BrainSpheres, 3D LUHMES

\footnotetext{
*Correspondence: leitepec@gmail.com; Ismirno1@jhu.edu

†Paulo Emílio Corrêa Leite, Mariana Rodrigues Pereira and Georgina Harris contributed equally to this work.

'Directory of Metrology Applied to Life Sciences - Dimav, National Institute of Metrology Quality and Technology - INMETRO, Av. Nossa Senhora das Graças 50, LABET - Dimav, Predio 27, Duque de Caxias, Xerem, Rio de Janeiro 25250-020, Brazil

${ }^{3}$ Center for Alternatives to Animal Testing (CAAT), Bloomberg School of Public Health, Johns Hopkins University, 615 N. Wolfe Street, Baltimore, MD 21205, USA

Full list of author information is available at the end of the article
}

(c) The Author(s). 2019 Open Access This article is distributed under the terms of the Creative Commons Attribution 4.0 International License (http://creativecommons.org/licenses/by/4.0/), which permits unrestricted use, distribution, and reproduction in any medium, provided you give appropriate credit to the original author(s) and the source, provide a link to the Creative Commons license, and indicate if changes were made. The Creative Commons Public Domain Dedication waiver (http://creativecommons.org/publicdomain/zero/1.0/) applies to the data made available in this article, unless otherwise stated. 


\section{Background}

Nanoparticles (NP) can be synthesized from different materials and have generated increasing interest in nanomedicine, mostly as drug delivery systems $[1,2]$. NP capable of delivering drugs exhibit advantages such as drug stability, increased bioavailability and reduced drug concentrations required to reach the target, thus decreasing side effects [3]. Some NP, including gold NP, have the ability to cross the blood brain barrier (BBB) and reach the central nervous system (CNS), providing promising drug delivery systems (especially for the treatment of CNS diseases [3-8]). NP surface modification by adding specific targeting ligands can enhance their BBB penetration and contribute for cellular uptake. NP size, shape, surface, charge and modification with cellpenetration peptides matter for cellular uptake and fate. Commonly, smaller NPs are better internalized with higher percentage of biodistribution [9-11] and display more ability for $\mathrm{BBB}$ penetration and distribution in the CNS $[12,13]$. Positively charged NPs are more easily internalized than neutral and negatively NPs [14]. In this sense, NP may serve as an important alternative for invasive CNS procedures such as implantation of catheters, imaging and therapy of brain tumors, and improvement of drug delivery [3, 15-17].

However, toxic effects of nanomaterials have been described [1], including induction of oxidative stress, inflammation [18], DNA damage, and alterations in gene expression [19]. We found earlier, for example, that cobalt nanoparticles were able to induce cell transformation, a hallmark of cancer, in contrast to cobalt ions [20]. NP can also promote neurotoxic effects such as neuroinflammation and neurodegeneration [21]. Despite gold NP (Au-NP) being one of the mostly commonly used nanomaterials (due to their versatility in particle size and surface modification) and their biocompatibility for applications such as drug and gene delivery [22], they can induce toxicity in different cellular models [23]. In addition, studies have shown that $\mathrm{Au}-\mathrm{NP}$ induce apoptosis via caspase-dependent mechanisms as well as increase cell susceptibility to apoptosis induced by other agents [24, 25].

Polylactic acid NP (PLA-NP) is widely used as an alternative for drug delivery, including CNS. PLA-NP allow sustained therapeutic drug levels for longer periods due to their polymeric matrix that prevents drug degradation, allowing better release kinetics. The surface functionalization of PLA-NP with specific targeting ligands such as sialic acid and glycopeptides enhances their ability to cross the $\mathrm{BBB}[5,26]$. For instance, chitosan coating promote positive surface charge to PLA-NP, resulting in enhanced cell uptake [27]. In addition, PLANP exhibit biodegradable characteristics (unlike the metallic ones) [28]. A detailed evaluation of neurotoxicity mediated by different NP that are designed to be drug carriers in the CNS, is necessary and will contribute to the development of safer nanocarriers.

The current bioengineering revolution of cell culture makes organotypic cell models, which overcome many limitations of traditional cell culture, increasingly available [29]. Three-dimensional (3D) in vitro models are the most novel approach in this development, as they present closer cell-to-cell interactions, often include different cell types, and can better reproduce in vivo physiology [30-33]. 3D CNS cultures have demonstrated advantages compared to two-dimensional (2D) cultures, such as increased cell survival and differentiation and better reproduction of electrical activity [30, 34]. Moreover, NP delivery efficacy differs dramatically between 2D and 3D culture systems [35]. In addition, the use of 3D CNS models derived from human cells, especially human pluripotent stem cells, provide more humanrelevant data compared to animal models, due to interspecies differences [36]. Although, animal models used for systemic toxicity, NP uptake, distribution in different organs, internalization and stability studies, provide useful and important information, the human physiology and kinetics should be taking in account. Thus, more advanced human relevant models such as organ-on-achip technology, where several organotypic human cultures are combined on a chip, are the future of drug delivery and nanotoxicity studies [37, 38]. Also, this will scale-up the testing, since traditional animal testing is time-consuming expensive and low-throughput.

Taking in account the advantages of 3D organotypic cultures, increasing number of studies have used variety of such models to study nanotoxicity and NP neurotoxicity [39-43]. Hoelting and collaborators developed an in vitro 3D neuronal model derived from human embryonic stem cell (hESC) and showed that polyethylene NPs (PE-NP) penetrated into the neurospheres and impacted gene expression at non-cytotoxic concentrations [42]. In the same way, Zeng and collaborators developed an in vitro 3D model of human neural progenitor cells and showed that different types of polyamidoamine dendrimers NPs can penetrate into neurospheres, affecting cell proliferation and migration through different pathways [43]. To the best of our knowledge, toxicity of gold and PLA-NP were not extensively studied in 3D brain models. However, they represent a potential group of NP that can be used for drug delivery in CNS, therefore, studying their neurotoxicity is essential [44, 45]. The toxicity of Au-NPs and PLA-NPs for CNS were previously investigated in vivo. Injection of $\mathrm{Au}-\mathrm{NP}$ did not promote morphological modifications or death in mice retinal cells [46]. However, Au-NP treatment in rats increased the number of GFAP- positive astrocytes in hippocampus and cerebral cortex. In addition, an 
increasing diameter of cell body and length of foot process of astrocytes in animals challenged with $\mathrm{Au}-\mathrm{NP}$ was observed [47]. PLA-NPs, polymeric NPs did not show in vivo toxicity and considered to be relatively safe. For example, Bejjani et al. have shown that these NPs did not alter rat retinal structure or induced cell death after intraocular injection [48]. However, it should be noted that PLA-NP were not investigated as extensively as Au-NP.

Both NPs are used for in vivo drug delivery. Previously, Au-NPs were used to IgG delivery in rabbit retina [49] and as adjuvant to improve immunization in spinal cord of injured rats [50]. PLA-NPs were used to carry Gag p24 HIV-1 antigen to increase immune response in mice [51] and T-cell responses on HIV-infected patients [52]. PEG-PLA-NPs were also used to delivery betamethasone in cochlea, promoting attenuation of cochlear hair cells loss induced by traumatic noise in mice [53].

Thus, in this study we focused on two types of NP: the metallic Au-NP already widely used for drug delivery and the biodegradable PLA-NP. We evaluated cellular effects of Au-NP functionalized with sodium citrate (Au-SC) and polyethylene glycol (Au-PEG), and PLANP, using two human 3D CNS in vitro models: (i) 3D LUHMES (Lund human mesencephalic) spheroids and (ii) human iPSC-derived brain spheroids (BrainSpheres). Both models have shown to be reproducible in content, size and shape; forming spheroids of approximately 250 and $350 \mu \mathrm{m}$, respectively [54]. LUHMES is an immortalized dopaminergic precursor cell line, derived from healthy human 8-week-old embryonic mesencephalic tissue, which rapidly differentiates into pure dopaminergic neurons $[55,56]$. BrainSpheres derived from human iPSCs is a multicellular 3D brain model that contains various types of neurons, astrocytes, and oligodendrocytes, and show spontaneous electrical activity and myelination [54, 57]. By using these two models in parallel, we can compare a single-cell type 3D model with a more complex 3D system. After NP characterization, we evaluated NP uptake, morphological and molecular alterations such as viability and mitochondrial membrane potential, genes related to cytotoxicity and oxidative stress and secretion of cytokines, chemokines, and growth factors in both 3D models.

\section{Results}

\section{NP characterization}

In order to assess NP diameter, micrographs of $\mathrm{Au}-\mathrm{SC}$ (Fig. 1a), Au-PEG (Fig. 1b) and PLA-NP (Fig. 1c) were acquired by TEM. Diameter of Au-SC, Au-PEG and PLA-NP was $17.5 \pm 1.4,5.4 \pm 0.7$ and $67 \pm 3 \mathrm{~nm}$, respectively (Fig. 1d). Hydrodynamic diameter of $6 \mu \mathrm{g} / \mathrm{mL} \mathrm{Au}$ SC and $20 \mu \mathrm{g} / \mathrm{mL}$ PLA-NP was assessed by DLS in medium without cells just after dilution and was $27 \pm 1$ and $116 \pm 1.5 \mathrm{~nm}(0 \mathrm{~h}, 3 \mathrm{D}$ LUHMES medium $)$ and $21 \pm 2$ and $62 \pm 2 \mathrm{~nm}(0 \mathrm{~h}$, BrainSpheres medium), respectively. Although, Au-SC and PLA-NP were larger in 3D LUHMES medium at $0 \mathrm{~h}$, the diameters of these NP remained stable after 24 and $72 \mathrm{~h}$. In contrast, $\mathrm{Au}-\mathrm{SC}$ and PLA-NP diameters increased over time (Au-SC: 29 $\mathrm{nm}$ at $24 \mathrm{~h}$ to $38 \mathrm{~nm}$ at $72 \mathrm{~h}$; PLA-NP: $99 \mathrm{~nm}$ at $24 \mathrm{~h}$ to $137 \mathrm{~nm}$ at $72 \mathrm{~h}$ ) in BrainSpheres differentiation medium (Fig. 1e). Due to the small diameter of Au-PEG $(\sim 5 \mathrm{~nm})$, they fall below the accurate range for DLS, as previously informed by the Au-PEG manufacturer, and therefore this measurement was not obtained for this NP type.

\section{D LUHMES and BrainSpheres production}

3D LUHMES and BrainSpheres were produced by constant gyratory shaking as previously described [54, 56, 58-60]. Both LUHMES and BrainSpheres are highly reproducible in size (200-250 $\mu \mathrm{m}$ for LUHMES and 300$350 \mu \mathrm{m}$ for BrainSpheres) and cellular composition from batch to batch and experiment to experiment. Due to their small size they do not develop a necrotic core as many bigger in size organotypic models do $[54,56,58-$ 60]. That makes these two models very suitable to use for neurotoxicological studies. At day 7 of differentiation, 3D LUHMES expressing RFP (red fluorescent protein) exhibited neuronal morphology with several cell projections and expressed markers of mature neurons, such as MAP2, neurofilament and synaptophysin (Fig. 2a). At 4 weeks of differentiation, BrainSpheres expressed different neural markers consistent with phenotypes of neurons ( $\beta$-tubulin, neurofilament, synaptophysin, PSD95), astrocytes (GFAP) and oligodendrocytes (O4), as shown in Fig. 2b).

\section{NP uptake in 3D LUHMES and BrainSpheres}

Since PLA-NP are conjugated to green fluorescent dye, coumarin-6, we analyzed their penetration into the spheroids by confocal imaging and flow cytometry. After $72 \mathrm{~h}$ exposure, uptake of $20 \mu \mathrm{g} / \mathrm{mL}$ PLA-NP by BrainSpheres (Fig. 3a) and 3D RFP-positive LUHMES (Fig. 3b) was visualized by confocal imaging. For better visualization, BrainSpheres were stained for neuronal (MAP2), astrocyte (GFAP) and oligodendrocyte (OLIG1) markers and show even distribution of PLA-NP throughout spheroids reaching the core. The Additional files 1 and 2 show the internalization of PLA in RFPpositive LUHMES in more details (see Additional files 1 and 2).

In order to quantify the internalization and also demonstrate concentration-dependent internalization, we performed flow cytometry that allows to measure colocalization of red signal from RFP protein in LUHMES and green signal from PLA-NP. Thus, RFP-expressing 


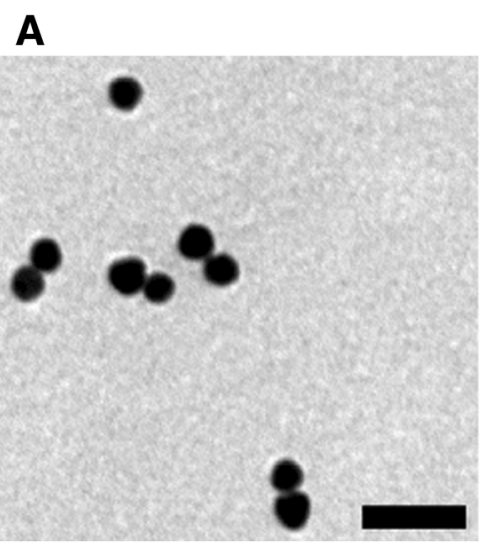

C

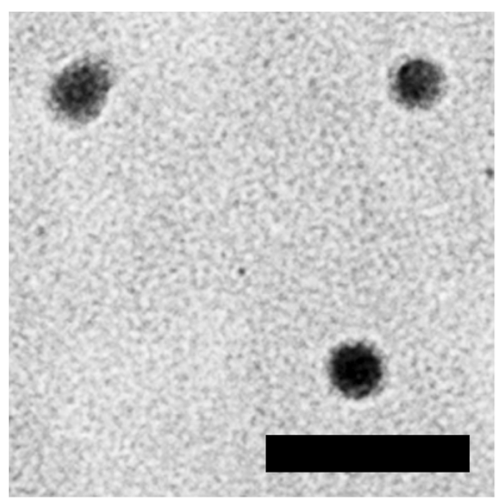

E
B

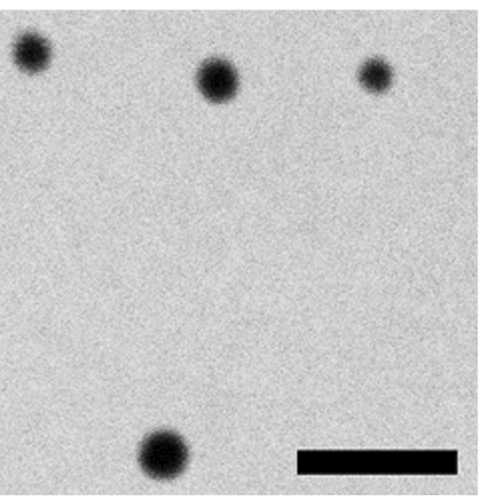

D

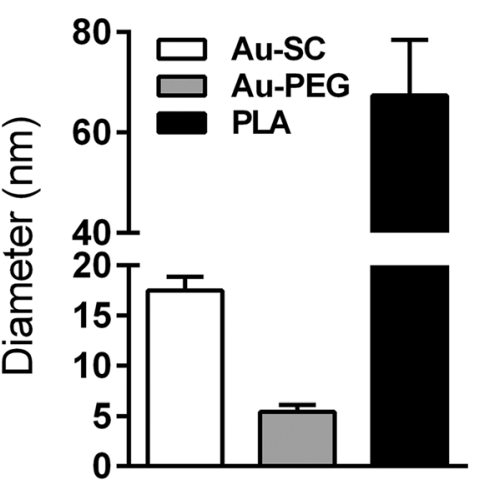

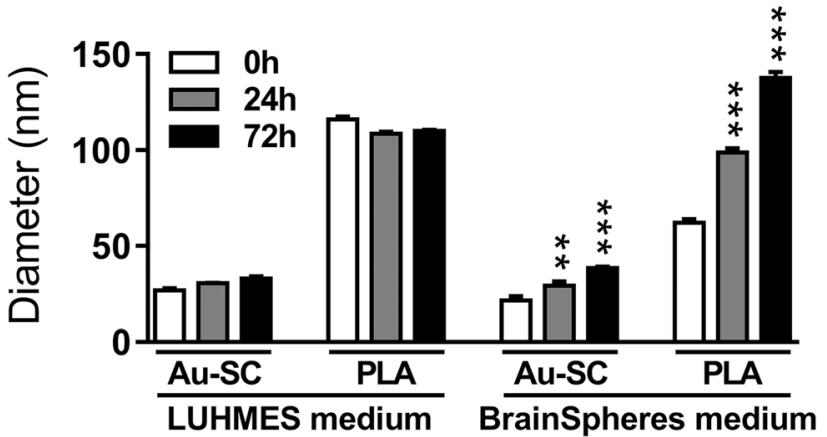

Fig. 1 NP characterization. Representative images obtained by TEM of a Au-SC, b Au-PEG and c PLA-NP. d Quantification of NP size by TEM. e Zaverage hydrodynamic diameter values of $6 \mu \mathrm{g} / \mathrm{mL}$ Au-SC and $20 \mu \mathrm{g} / \mathrm{mL}$ PLA-NP diluted in LUHMES and BrainSpheres culture media, analyzed by DLS after 0,24 and $72 \mathrm{~h}$ of incubation. Results are expressed as mean ( $\pm S D$ ). Each experimental group corresponds to the analysis of three independent experiments with three replicates. Statistical significance was analyzed by one-way ANOVA followed by Bonferroni's multiple comparisons post-test $\left({ }^{* *} p<0.01,{ }^{* * *} p<0.001\right)$. Scale bar a $100 \mathrm{~nm}, \mathbf{b} 25 \mathrm{~nm}$ and $\mathbf{c} 200 \mathrm{~nm}$

3D LUHMES were exposed to $0,0.2,2$, and $20 \mu \mathrm{g} / \mathrm{mL}$ PLA-NP for $72 \mathrm{~h}$, then spheroids were dissociated and fixed for subsequent analysis of co-localization between RFP (red) and PLA-NP (green) using flow cytometry. Results indicated increased co-localization between PLA-NP and RFP-expressing LUHMES cells in a concentration-dependent manner. Only $7.2 \%$ cells showed co-localization after exposure to $0.2 \mu \mathrm{g} / \mathrm{mL}$ while $96 \%$ cells co-localized with PLA-NP at $2 \mu \mathrm{g} / \mathrm{mL}$, reaching $100 \%$ at $20 \mu \mathrm{g} / \mathrm{mL}$ (Fig. $3 \mathrm{c}$ and Additional file 3 Figure S1A). In addition, we assessed internalization with ImageStreamX Mark II imaging flow cytometer (Amnis), which allows not only to analyze the shift of the fluorescence intensities but also to obtain an image of every cell in the flow and analyze intracellular localization of NP. Trypan blue staining was included to quench autofluorescence and fluorescence of NPs, which might be just attached to the outer side of the 

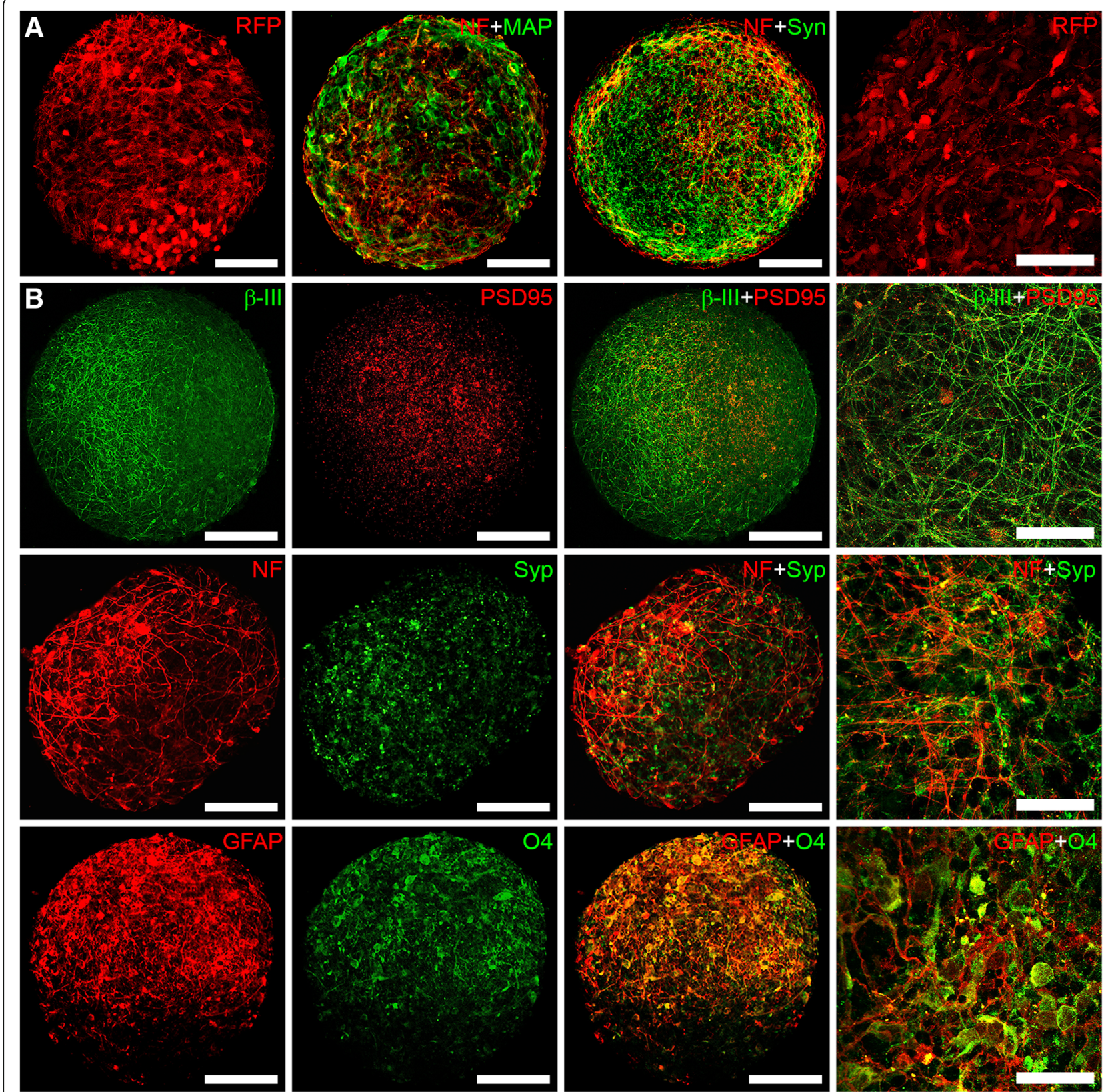

Fig. 2 Confocal Images of a LUHMES after 7 days of differentiation, expressing RFP or stained with neuronal markers MAP2 (green), neurofilament (red), synaptophysin (green); and b 4-week BrainSpheres expressing different neural cell type markers: $\beta$-III- tubulin/PSD95, neurofilament/ synaptophysin, GFAP/O4. Scale bars $100 \mu \mathrm{m}$ for the first three panels and $50 \mu \mathrm{m}$ for the last panel with higher magnification

membrane. Additional file 3: Figure $\mathrm{S} 1 \mathrm{~B}$ and $\mathrm{C}$ show representative images of unstained RFP-LUHMES and RFP- LUHMES treated with $20 \mu \mathrm{g} / \mathrm{mL}$ PLA NP for $24 \mathrm{~h}$ respectively. The punctuated staining inside the cells indicates internalization of PLA NP. Treatment with trypan blue did not shift the green fluorescence intensity significantly (compare median of RFP + PLA $(14,014)$ vs. RFP + PLA + Trypan $(11,989)$ suggesting that the green fluorescence signal is coming from the inside of the cells (Additional file 3: Figure S1D). Altogether, these data showed that NP penetrated throughout both models; although some NPs remained in the extracellular space, some PLA-NP were internalized by cells throughout the spheroids.

$\mathrm{Au}-\mathrm{SC}$ and Au-PEG in both 3D models were assessed by ICP-MS, a method to study cellular uptake of metallic NP [61-64]. Our results showed Au-NP uptake in both models after 24 and $72 \mathrm{~h}$ exposure. Uptake of both $\mathrm{Au}$ NP types was delayed in 3D LUHMES (increased after $72 \mathrm{~h}$ vs. $24 \mathrm{~h}$ exposure). In BrainSpheres, Au-SC uptake 

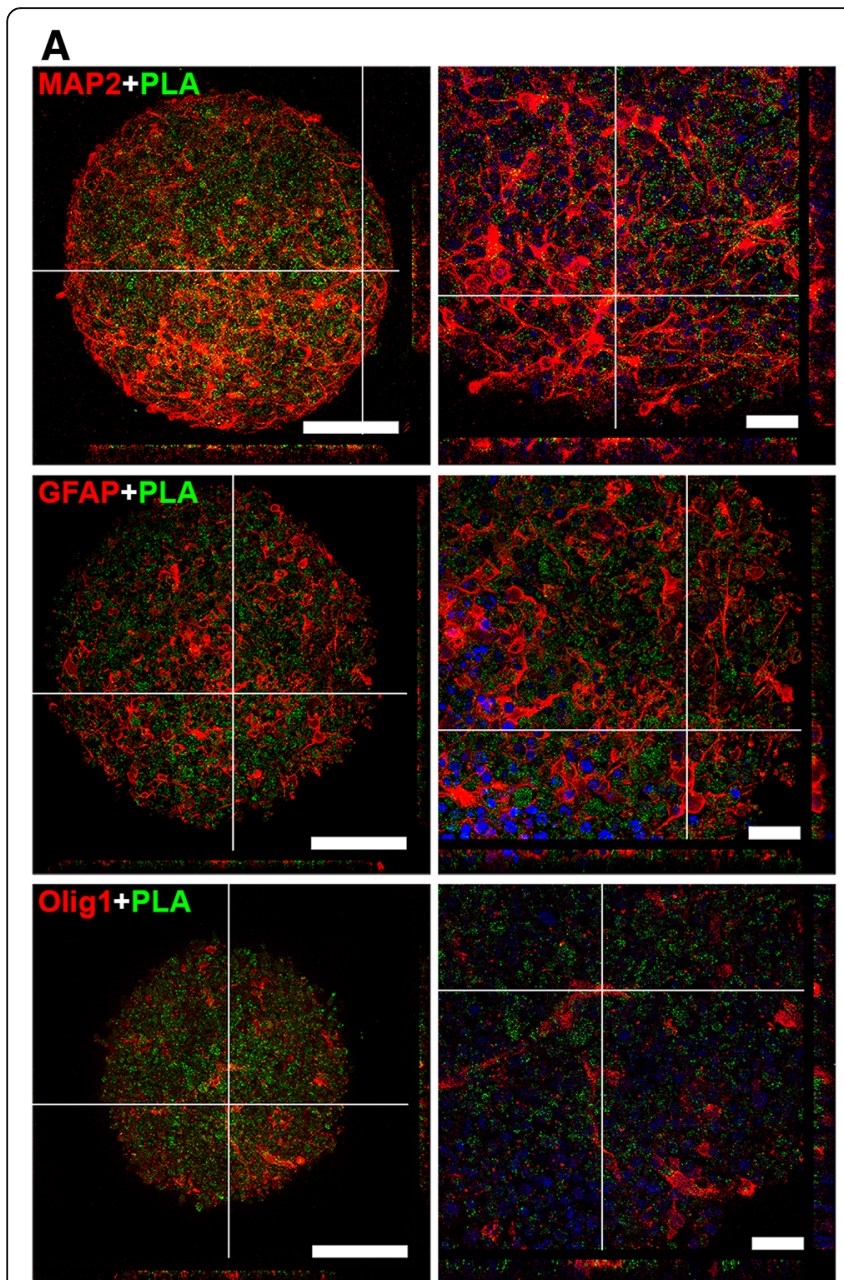

B
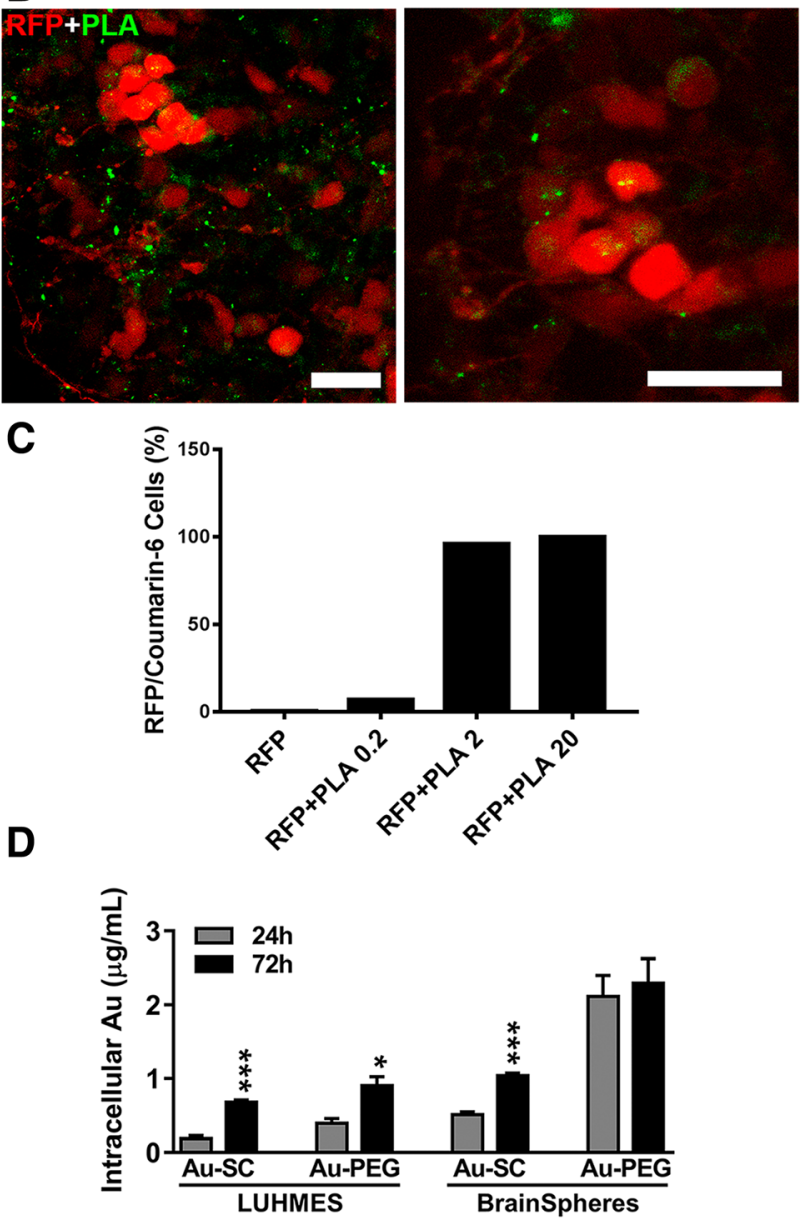

Fig. 3 NP uptake by 3D LUHMES and BrainSpheres. Representative images acquired by confocal microscope after $72 \mathrm{~h}$ exposure to $20 \mu \mathrm{g} / \mathrm{mL}$ PLA-NP (green) of a BrainSpheres stained with MAP2, GFAP, OLIG-1 (red) and Hoechst33342 (blue nuclei), with the Scale bars $100 \mu \mathrm{m}$ (left panels) and $25 \mu \mathrm{m}$ (right panels); and b 3D RFP-LUHMES (red), PLA-NP (green), scale bar $20 \mu \mathrm{m}$. c Flow cytometry of RFP-LUHMES, treated with 0, 0.2, 2 and $20 \mu \mathrm{g} / \mathrm{mL}$ PLA-NP. Red and green fluorescence was quantified in FL2 and FL1 channels, respectively. The bars represent \% of RFP/PLA double positive cells in each sample. $\mathbf{d}$ Intracellular levels of Au in 3D LUHMES and BrainSpheres after 24 and $72 \mathrm{~h}$ exposure to $6 \mu \mathrm{g} / \mathrm{mL} \mathrm{Au-SC}$ and $20 \mathrm{\mu g} / \mathrm{mL}$ Au-PEG quantified by ICP-MS. Results are expressed as mean ( \pm SEM). Each experimental group corresponds to the analysis of three independent experiments with three replicates. Student's $t$-test was used to compare 24 and $72 \mathrm{~h}$ treatment groups $\left({ }^{*} p<0.05,{ }^{* * *} p<0.001\right)$.

increased after $72 \mathrm{~h}$ compared to $24 \mathrm{~h}$, while levels of internalization of Au-PEG at 24 and $72 \mathrm{~h}$ exposure time points were similar (Fig. 3d). Although, due to method limitations we cannot exclude the possibility of Au-NP absorption on the surface of the cells. The viability tests performed below indirectly confirm the presence of the Au-NP within the cells.

\section{Effects of NP on mitochondrial membrane potential} (MMP) and cell viability in both 3D human neural models Both 3D LUHMES and BrainSpheres were exposed to PLA, Au-SC, and Au-PEG at different concentrations for 24 or $72 \mathrm{~h}$, followed by analysis of MMP using MitoTracker $^{\oplus}$ Red CMXRos (Fig. 4a, b). After $24 \mathrm{~h}$ exposure to 0.6 and $6 \mu \mathrm{g} / \mathrm{mL} \mathrm{Au}-\mathrm{SC}$, MMP was reduced in both models in a concentration-dependent manner (Fig. 4b). After $72 \mathrm{~h}$, a further decrease in MMP was observed in 3D LUHMES while BrainSpheres showed reduction only at $6 \mu \mathrm{g} / \mathrm{mL}$. After $24 \mathrm{~h}$ exposure, only the highest concentration of Au-PEG $(20 \mu \mathrm{g} / \mathrm{mL})$ led to reduced MMP levels in 3D LUHMES, with no significant reduction at $72 \mathrm{~h}$ exposure. On the contrary, BrainSpheres showed a strong concentration-dependent reduction of MMP after 24 and $72 \mathrm{~h}$ exposure to Au-PEG. PLA-NP reduced MMP in 3D LUHMES at all concentrations after $24 \mathrm{~h}$ exposure, which reversed at $0.2 \mu \mathrm{g} / \mathrm{mL}$ and further decreased at 2 and $20 \mu \mathrm{g} / \mathrm{mL}$ after $72 \mathrm{~h}$ exposure. MMP of BrainSpheres was not affected by any of the PLA-NP tested concentrations. Taken together, we observed stronger acute than prolonged effects of tested NP on 


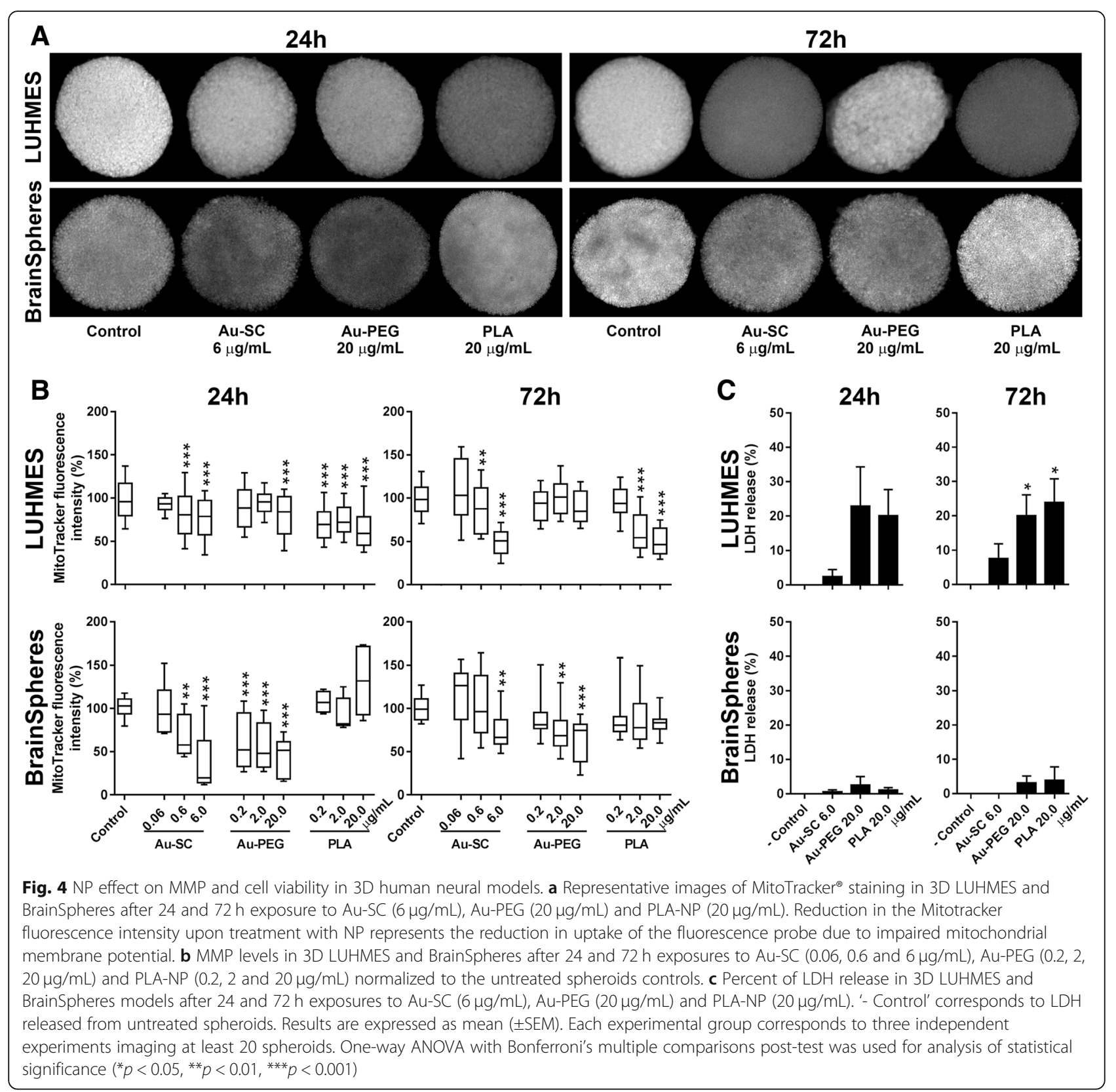

mitochondria functionality in BrainSpheres, while 3D LUHMES sensitivity to these NP was generally amplified with increased exposure concentrations and time. These data suggest different susceptibility of these $3 \mathrm{D}$ models to the studied nanomaterials, most probably due to the differences in cellular complexity of the models (Fig. 4a, b).

LDH release, a marker of cellular membrane damage and cell death, was measured at the highest concentrations of NP. The viability of 3D LUHMES was significantly affected $(\sim 25 \%$ cell death $)$ by Au-PEG and PLA-NP after $72 \mathrm{~h}$ exposure. The studied NP did not affect BrainSpheres viability at the tested concentrations (Fig. 4c).
As expected, reduction in MMP was observed even without significant LDH release. Since mitochondria membrane depolarization occurs much earlier than cellular membrane lysis in the cascade of cell death events, it can be reversible [65-67], and, therefore, does not necessarily lead to cell death.

\section{Morphology changes in 3D LUHMES and BrainSpheres after NP treatment}

The morphology of both spheroid models was analyzed by scanning electron microscopy (SEM) after $72 \mathrm{~h}$ treatment with the highest NP concentrations (Au-SC $(6 \mu \mathrm{g}$ ) $\mathrm{mL})$, Au-PEG $(20 \mu \mathrm{g} / \mathrm{mL})$ and PLA-NP $(20 \mu \mathrm{g} / \mathrm{mL}))$. 
Morphology of 3D LUHMES was affected by Au-PEG and PLA-NP, but not by Au-SC. Significant cell debris attached to the spheroids and less neuronal projections were observed (Fig. 5, depicted with arrowheads). BrainSpheres did not show any alterations under the investigated conditions, which correlates with above cytotoxicity data (Fig. 5).

\section{NP effect on expression of oxidative stress related genes in BrainSpheres}

We further investigated changes in gene expression related to ROS regulation: SOD1, SOD2, NF2L2, GSTO1, and NFR1 are involved in antioxidant responses and CLEC7A is associated with ROS production and inflammation. BrainSpheres and 3D LUHMES were exposed to $\mathrm{Au}-\mathrm{SC}(6 \mu \mathrm{g} / \mathrm{mL})$, Au-PEG $(20 \mu \mathrm{g} / \mathrm{mL})$, and PLA-NP $(20 \mu \mathrm{g} / \mathrm{mL})$ for $72 \mathrm{~h}$, then gene expression was analyzed by Real-Time qPCR. In BrainSpheres, SOD1 expression was increased by Au-SC and Au-PEG, but not PLA, whereas NF2L2 was increased only by Au-PEG. NFR1 expression was up-regulated by Au-PEG and PLA-NP, while expressions of GSTO1 and CLEC7A were upregulated by all NP. SOD2 expression was not altered upon NP challenge (Fig. 6). These data showed that the exposure of BrainSpheres to NP increased expression of genes related to oxidative stress protection in BrainSpheres, and the strongest effect was observed with $\mathrm{Au}$ PEG, in line with the higher uptake of this NP. The perturbations in 3D LUHMES were less dominant. No significant effects on the expression of $S O D 1, S O D 2$ and GSTO1 were observed; CLEC7A was undetermined. $N F 2 L 2$ was slightly elevated by AU-PEG, while NFR1 expression was downregulated by AU-SC and Au-PEG NP (Additional file 4: Figure S2).

\section{NP influence on release of chemokines, cytokines and growth factors in 3D human neural models}

Analysis of multiple secreted products from both 3D models exposed to $6 \mu \mathrm{g} / \mathrm{mL} \mathrm{Au-SC,} 20 \mu \mathrm{g} / \mathrm{mL} \mathrm{Au}-\mathrm{PEG}$ or $20 \mu \mathrm{g} / \mathrm{mL}$ PLA-NP for 24 and $72 \mathrm{~h}$ showed alterations in the levels of some mediators (Fig. 7). In general, neural cells produce lower levels of chemokines and cytokines compared to cells of the immune system, but such levels are critical to maintaining their homeostasis and, consequently, the microenvironment. Thus, any imbalance may affect their physiological behavior [68].

From all conditions tested, Au-PEG had the strongest effect on cytokines release in 3D LUHMES cultures. It significantly downregulated the levels of all cytokines tested. No significant changes in cytokine release were observed in LUHMES cultures treated with Au-SC and PLA-NP (Fig. 7a). TGF- $\beta 1$, TGF- $\beta 2$, and TGF- $\beta 3$ levels were not significantly altered in 3D LUHMES (Additional file 5: Figure S3).

BrainSpheres were not as sensitive to Au-PEG with only two cytokines (IL-10, IL12p70) and two growth factors (bFGF, VEGF) downregulated in these cultures, while IL1ra was upregulated by Au-PEG and PLA-NP. In addition, $\mathrm{Au}-\mathrm{SC}$ reduced the levels of IL12p70 and VEGF in BrainSpheres (Fig. 7b). In BrainSpheres, TGF- $\beta 1$ levels were reduced by $\mathrm{Au}-\mathrm{SC}$ and Au-PEG after $72 \mathrm{~h}$. These NP also eliminated TGF- $\beta 3$ in the first $24 \mathrm{~h}$, but not after $72 \mathrm{~h}$. PLA-NP did not affect the levels of these soluble mediators (Fig. 8). Altogether, these data suggested different responses in the profile of chemokines, cytokines, and growth factors to the studied nanomaterials in both models, which are both devoid of immune cells. The very low levels and frequent reductions in cytokine levels compared to control are difficult to interpret. However, there seems to some correspondence of cytokine patterns in response to the NP between the two models, which corroborates the findings. At this stage, these findings are descriptive and mainly illustrate that cytokines could be highly sensitive quantitative biomarkers for perturbation of cells by NP. Further work is needed to understand the mechanism and relevance of these changes.

\section{Discussion}

The use of NP as carriers promises advantages such as better drug stability, bioavailability, improved dosing and

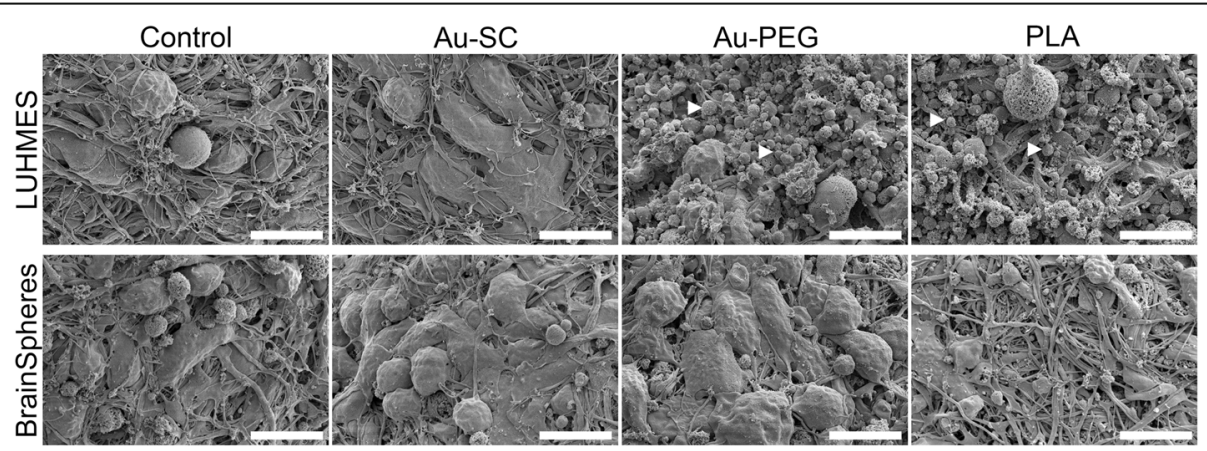

Fig. 5 Morphology of 3D LUHMES and BrainSpheres exposed to Au-SC $(6 \mu \mathrm{g} / \mathrm{mL})$, Au-PEG $(20 \mu \mathrm{g} / \mathrm{mL})$ and PLA-NP $(20 \mu \mathrm{g} / \mathrm{mL})$ for $72 \mathrm{~h}$. Control represents untreated spheroids. White arrowheads indicate cell debris. Scale bars $10 \mu \mathrm{m}$ 

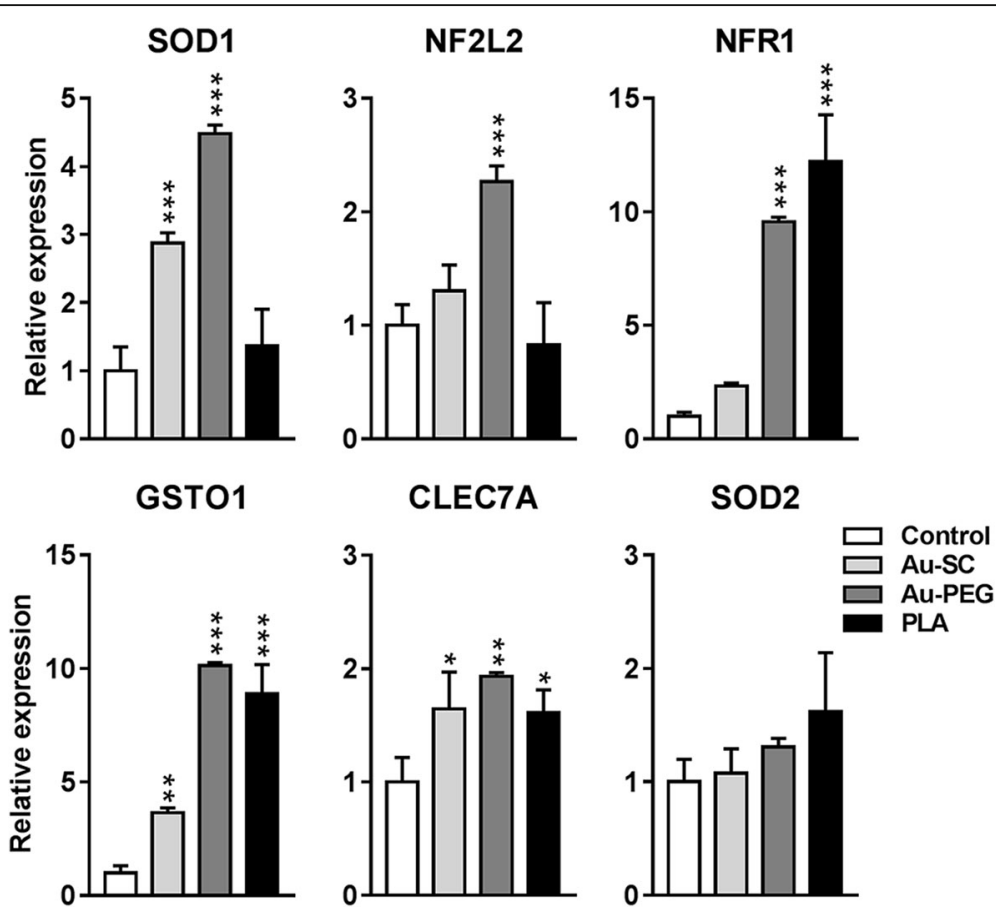

Fig. 6 Effect of NP on expression of genes related to ROS regulation in BrainSpheres. Graphs showing the relative expression of SOD1, SOD2, NF2L2, GSTO1, NFR1 and CLEC7A after exposure to Au-SC $(6 \mu \mathrm{g} / \mathrm{mL})$, Au-PEG $(20 \mu \mathrm{g} / \mathrm{mL})$ and PLA-NP $(20 \mu \mathrm{g} / \mathrm{mL})$ for $72 \mathrm{~h}$ normalized to the expression of the genes in the untreated control spheroids. Data was collected from three independent experiments and represents fold changes (FC \pm SEM, $n=3)$. One-way ANOVA with Bonferroni's multiple comparisons post-test was used to analyze the statistical significance $\left({ }^{*} p<0.05\right.$, $\left.{ }^{* *} p<0.01,{ }^{* * *} p<0.001\right)$

reduced side effects. Many NP drug delivery systems are being developed, such as Au-NP conjugated to siRNA against NADPH Oxidase 4, Au-NP carrying plasmid DNA encoding for murine IL-2, PLA-NP carrying Gag p24 HIV-1 antigen, B6 peptide conjugated to PEG-PLANP encapsulating the neuroprotective peptide NAPVSIPQ to Alzheimer's disease mice model, and others [51, 69-71]. However, nanotoxicity must be controlled before administration [3, 72]. From the variety of NP used for drug delivery, Au-NP are one of the most widely used [73]. However, recent studies have shown their potential to induce (neuronal) cytotoxicity and neuroinflammation $[23,24]$. PLA-NP emerged as an alternative for CNS drug delivery due to their biocompatibility, biodegradability, and drug release kinetics [74]. Therefore, in this study we decided to use Au-NP as a reference nanomaterial, since they are well established and described delivery system, and compare toxicity of $\mathrm{Au}-\mathrm{NP}$ with an alternative system - PLA-NP.

$\mathrm{NP}$ derived from different materials, including Au-NP and PLA-NP are able to cross the BBB, especially if modified with specific ligands, increasing the penetration efficiency. They reach the CNS what makes them excellent potential drug carriers for reaching the cerebral parenchyma [3, 5-8]. However, reported Au-NP toxicity to the CNS includes apoptosis and alterations in retinal layers structure, microglia activation, increase of neuronal excitability in CA1 region of hippocampus and the potential to aggravate seizure activity [75-77]. The use of PLA-NP for drug delivery is a relatively recent approach, showing positive results in treating hearing loss and Alzheimer's disease in animal models, without inducing toxicity [53, 71]. Functionalization of NPs is important to ensure their colloidal stability and biocompatibility. It should be kept in mind, that these surface modifications may affect cellular toxicity. For instance, cationic functionalization of Au-NPs is more toxic than the neutral and anionic ones, and toxicity will depend on the charge magnitude/intensity [78, 79]. Another study showed that citrate and biotin modified AuNPs were non-toxic up to higher concentrations, whereas CTAB functionalization was toxic [80]. NP used in this study were not functionalized with cytotoxicity inducing cationic ligands. No cytotoxicity was reported for PEG functionalization [81, 82].

Several 3D models have been developed and used to study NP toxicity, drug discovery and delivery [31, 33, 35, 37-40]. Human-derived 3D neural in vitro models, which mimic complex human CNS interactions are a promising tool [54, 83-85] that can be applied to study the potential cytotoxic effects of nanocarriers. The advantages of the two models presented here over the 


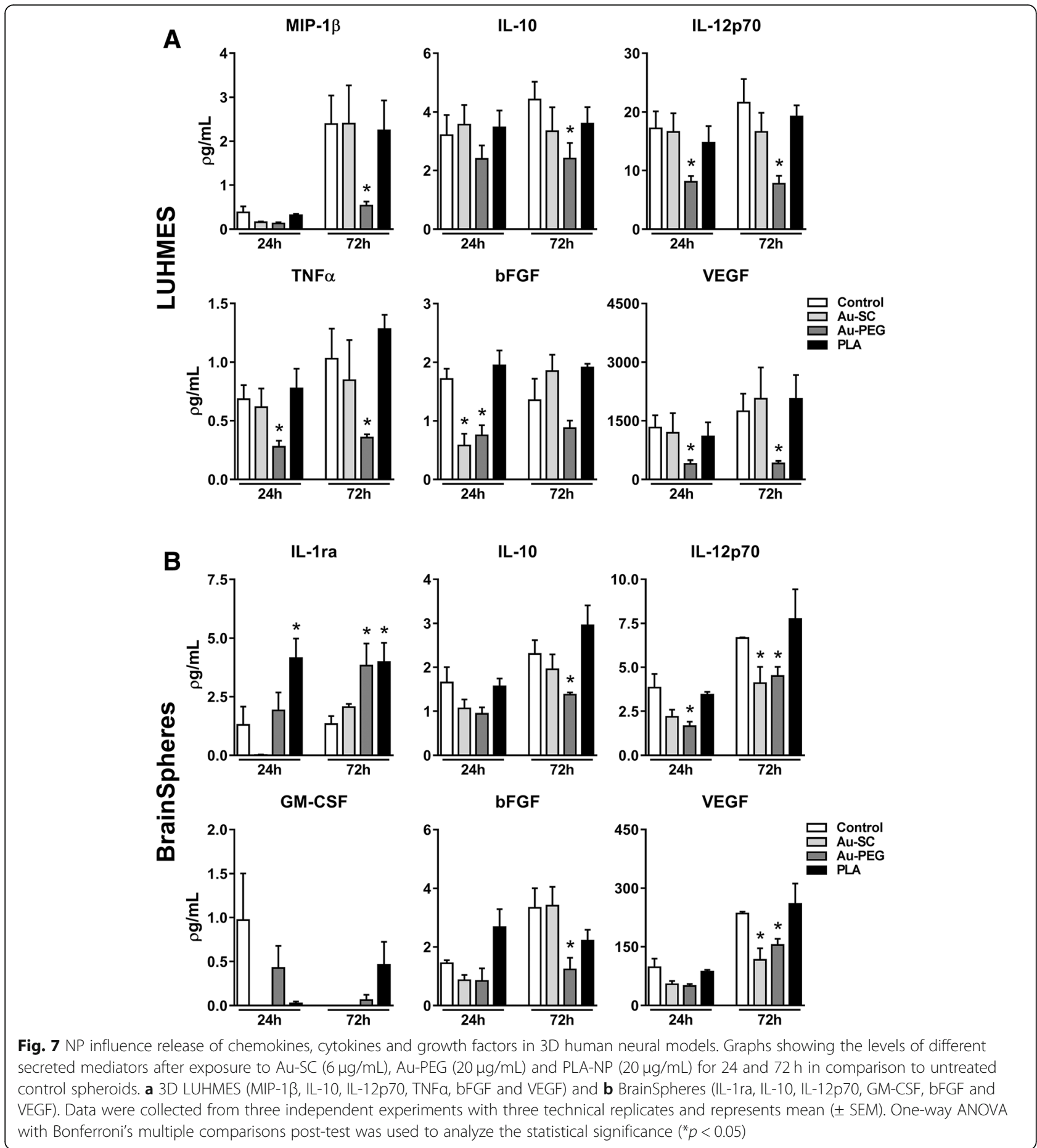

other existing in vitro organotypic brain models lie in the high standardization of the spheroid generation procedures: the spheres generated with gyratory shaking are very homogeneous in size, form and cellular composition as was shown in our previous publications $[54,56$, $58,59]$. Although, other brain organotypic models are more complex in representation of the organ morphology [84, 85], we have chosen the models described here because the homogeneity is a key feature in studying toxicity. In the future, administration of NP in the other brain organoids may confirm the findings presented here.

In this study we used Au-SC NP in concentrations up to $6 \mu \mathrm{g} / \mathrm{mL}$, Au-PEG and PLA up to $20 \mu \mathrm{g} / \mathrm{mL}$. The direct comparison of NP brain concentrations in vivo with in vitro nominal and final concentrations is challenging 


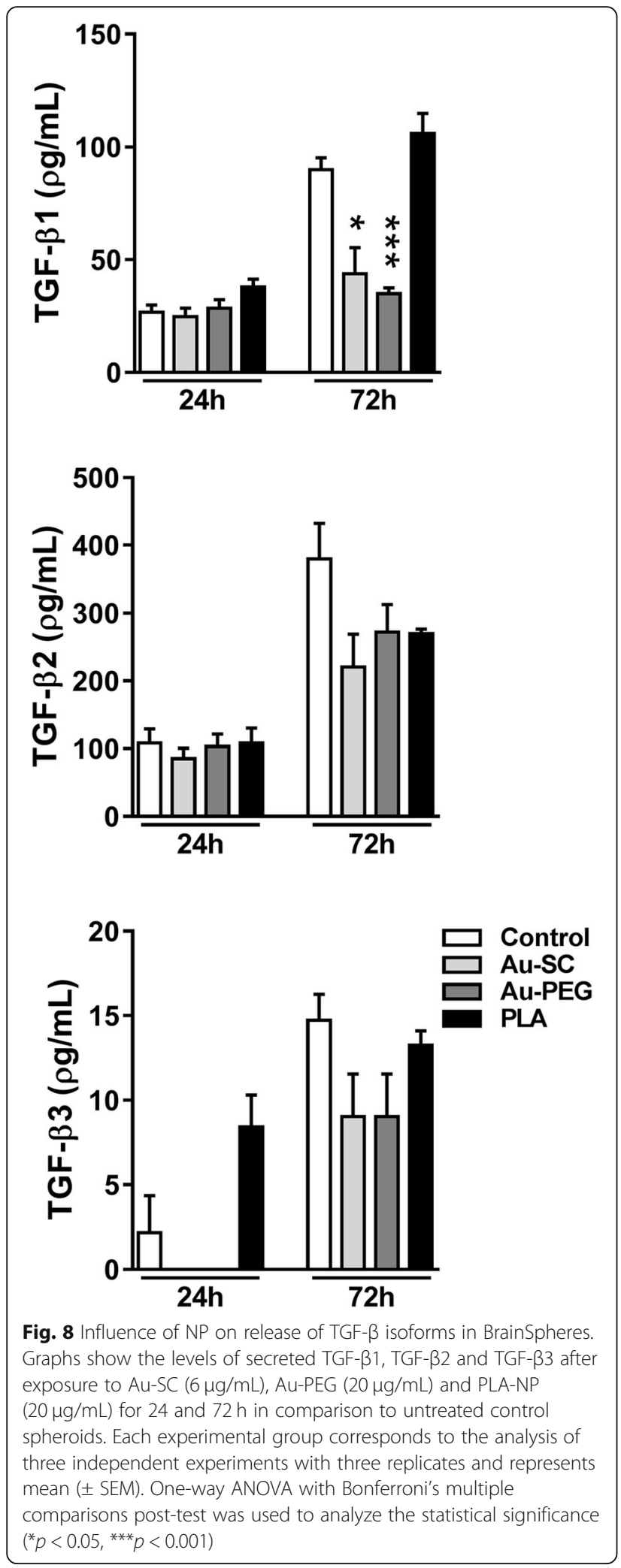

as well as quantification of final NP concentration in the target organ. However, there are studies that quantified the amounts of Au-NPs in the mice brain using ICPMS, the gold standard method for metallic detection in cells and organs. Khlebtsov and Dykman, 2011 adapted the results from [86] showing that after oral administration of $200 \mu \mathrm{g} / \mathrm{mL}$ Au-NPs with 4, 10 and $28 \mathrm{~nm}$ in size, these NPs were detected and quantified in the brain: from $10 \mathrm{ng} / \mathrm{mL}$ ( $4 \mathrm{~nm} \mathrm{Au-NPs)} \mathrm{to} 1 \mathrm{ng} / \mathrm{mL}(28 \mathrm{~nm} \mathrm{Au}$ NPs) [87]. Comparing to our data, we used $4 \mathrm{~nm} \mathrm{Au-}$ NPs in vitro and detected up to $1000 \mathrm{ng}$ in LUHMES and up to $2000 \mathrm{ng}$ in BrainSpheres per well (with around 50 LUHMES spheroids with $200-250 \mu \mathrm{m}$ in diameter and around 80 to 100 BrainSpheres with $300-350 \mu \mathrm{m}$ in diameter per well). (Fig. 3d). These NPs were detected in lung, heart, kidney, spleen, liver, small intestine and stomach in different concentrations [87]. It should be kept in mind that the $200 \mu \mathrm{g} / \mathrm{mL} \mathrm{Au}$-NPs in the aforementioned study were administrated via water bottles for 7 days, without control of daily ingestion. It is possible that Au-NPs may have precipitated and deposited on the bottom of the bottle that may result in lower concentrations of NP in target organs. Jain et al., have shown that rats treated intravenously with $60 \mu \mathrm{g} / \mathrm{mL}$ of PLA-NP had particles in the brain [88] besides accumulation in the liver, kidney, lungs, heart and spleen. However, since PLA NPs are not metallic and may degrade quickly, they cannot be detected by ICP-MS, that makes it difficult to measure their concentrations in the organs.

To characterize the interaction between NP, media and cells in vitro, we assessed NP size, penetration throughout the spheroids and internalization. Our NP characterization showed that Au-SC and PLA-NP did not change in size over time in LUHMES differentiation medium. Although, immediately after resuspension of NP in LUHMES differentiation medium, NP size was higher than previously measured by TEM in water, they were then stable in size for 24 and $72 \mathrm{~h}$ (Fig. 1c). However, in BrainSpheres differentiation medium, we observed a gradual increase in NP size for both Au-SC and PLA-NP. In both media, the immediate (3D LUHMES) or delayed (BrainSpheres) increase in NP size can be attributed to aggregation or the formation of a protein corona due to NP interaction with proteins in cell culture medium. It is possible that proteins from the medium supplements attach to the NP, affecting their hydrodynamic analysis. More work is needed within the characterization field to better predict how these media alter NP physico-chemical properties. Due to the proprietary composition of cell culture supplements, further analysis to identify these proteins was not possible. However, a protein corona could facilitate cellular NP uptake, as is known to occur in blood circulation [89]. Studying the composition of the protein corona would 
be necessary to assess and improve drug delivery for CNS therapies. A recent study showed that artificial apolipoprotein E4 adsorption to NP forming corona increases NP translocation through $\mathrm{BBB}$, improving the brain parenchyma accumulation threefold when compared to undecorated particles [90].

A major question for the use of 3D organotypic cultures to assess NP toxicity is, whether the NP can actually penetrate the spheroid and reach the inner cell mass. The 3D models, studied here, were, indeed, able to take up the three NP types. As quantified by flow cytometry, PLA-NP were internalized by LUHMES in a concentration-dependent manner, with $2 \mu \mathrm{g} / \mathrm{mL}$ being sufficient to penetrate $96 \%$ of cells. These results support the confocal images that showed PLA-NP in the core of both 3D models. Au-SC uptake was similar in both 3D models with increased levels after $72 \mathrm{~h}$. Au-PEG showed the same result as Au-SC in 3D LUHMES, but the uptake in BrainSpheres was 5-fold higher after $24 \mathrm{~h}$ and stabilized after $72 \mathrm{~h}$. The differences in Au-PEG internalization between the 3D models could be attributed to the presence of glial cells in BrainSpheres that may take up these NP more efficiently than neurons and/or regulate neuronal uptake as previously shown [91]. In fact, PEG functionalization contributes to a better NP uptake by neural cells, and their smaller diameter may be the reason for higher intracellular levels compared to Au-SC in BrainSpheres. This is in line with studies showing that PEGylation increases NP accumulation in the brain compared to non-PEG-coated NP [3, 92]. Therefore, PEG-coating and the presence of glial cells facilitating uptake could explain the high Au-PEG accumulation in BrainSpheres in the first $24 \mathrm{~h}$ and their maintenance until $72 \mathrm{~h}$.

Due to the efficient NP internalization by neural cells in the 3D models, their potential to induce nanotoxicity needs to be considered. In 3D LUHMES, Au-SC but not $\mathrm{Au}-\mathrm{PEG}$ significantly reduced mitochondria function (MMP). Au-PEG had only slight acute effects at the highest concentration tested, which was no longer significant after $72 \mathrm{~h}$ exposure. However, Au-PEG increased $\mathrm{LDH}$ release, possibly due to the high contact surface area of this NP that may contribute to neuronal lysis. In BrainSpheres, MMP was significantly reduced by both AuNP but no increase in LDH release was observed. In this model, glial cells may be involved in the AuNP clearance, reducing their availability and damage to neuronal cells.

PLA-NP reduced MMP and increased LDH release in 3D LUHMES, but showed no effect in BrainSpheres. The 3D LUHMES model is a monoculture model, consisting only of dopaminergic neurons, and may display higher susceptibility to harmful agents that induce mitochondrial damage, and cytotoxicity [93]. In fact, NP cytotoxicity has shown to be lower when neurons and astrocytes are co-cultured, compared to monocultures [94]. The absence of neuroprotective glial cells, together with the known susceptibility of dopaminergic neurons to mitochondria depletion, could contribute to the toxicity observed in this model from all studied NP. On the other hand, astrocytes in BrainSpheres as well as polymeric composition of PLA-NP may be critical to increase NP biocompatibility and cell tolerance. It is important to note that mouse prenatal exposure to NPs induces neurotoxicity during development and astrocytes reactivity. Maternal inhalation of carbon black increased GFAP levels in astrocytes from cortex and hippocampus offspring [95]. Indeed, exposition of mice from postnatal day $4-7$ and $10-13$, which is equivalent to human third trimester, to ultrafine particle air pollution promoted inflammation, neurotoxicity, gliosis and behavioral dysfunction [96]. In the line with that, we observed an increase in glia marker - S100 $\beta$ - after exposure of BrainSpheres to Au-PEG for $72 \mathrm{~h}$ (data not shown), suggesting an induction of gliosis by Au-PEG NP in BrainSpheres.

Mitochondrial dysfunctions are associated with ROS production, promoting cell stress and death [97]. NP can mediate this deregulation in neural cells [98]. Since AuNP decreased MMP without cell viability loss in BrainSpheres, we investigated the expression of genes involved in antioxidant responses and ROS production. Although all studied NP led to increased CLEC7A expression, related to ROS production and inflammation, SOD1, NF2L2, GSTO1, and NFR1, related to antioxidant responses in general, were increased by Au-PEG and PLA-NP but not by Au-SC. This activation of antioxidant genes may indicate that the cell activated antioxidant response as a reaction to the NP challenge in BrainSpheres. Different sources such as free radicals on NP surface and redox group from NP functionalization may cause the induction of ROS production and oxidative stress, depending on NP type. The differences of oxidative stress induction may activate different intracellular signaling pathways such as the activation of transcription factors and cytokines production and release [99].

These results showed that the studied NP do not necessarily induce toxicity directly but are able to unbalance cell physiology. Amongst these NP, Au-PEG had the strongest effect, in line with their increased uptake.

In BrainSpheres, exposure to NP did not decrease viability or lead to any apparent morphological alterations. However, AuNP affected mitochondrial activity and increased antioxidant genes with a possible activation of cell survival programs, which may be sufficient to maintain cell viability and morphology. In contrast, 3D LUHMES exposed to Au-PEG and PLA-NP showed 
morphological alterations on the surface of spheroids, which was confirmed by cell death measured by LDH release. These results reinforce the impact of glial cells in NP tolerance to toxic insults.

Glial and neuronal cells produce and secrete factors to maintain survival. Some of them are considered proinflammatory, but also important at physiological levels for neuron-glia communication [100]. The level of these factors can be altered in response to harmful agents. AuPEG reduced most detected cytokines, chemokines, and growth factors in both 3D models. In 3D LUHMES, a reduction in MIP-1 $\beta$, IL-10, IL-12p70, TNF $\alpha$, bFGF and VEGF levels are in line with the observed effects on viability. In BrainSpheres, Au-PEG reduced the levels of IL10 , IL-12p70, bFGF, VEGF, and TGF- $\beta 1$, as well as increased the IL-1ra levels. Au-SC affected fewer secreted mediators, probably due to their smaller contact area and low cell penetration rate compared to PEGylated AuNP. In CNS, IL-12 is manly related to pathogenesis of autoimmune diseases; VEGF to neurogenesis, neuronal migration, neuroprotection, and blood vessel growth; and TGF- $\beta 1$ displays neuroprotective role and promotes glial scar and fibrosis, induced by acute and chronic brain injury [101-103]. IL-10 is an important antiinflammatory mediator. The reduced levels of such mediators suggest that AuNP in a first interaction with neural cells may turn them susceptible to other subsequent harmful agents in the CNS. However, such alterations together with reduced MMP were not sufficient to induce cell death in BrainSpheres, possibly due to the increased expression of antioxidant genes and the neuroprotective role of astrocytes that may maintain cell survival.

PLA-NP had minimal effects on secreted cytokines, chemokines, and growth factors, restricted to IL-1ra increase in BrainSpheres. IL-1ra binds to IL-1 receptor in cell membranes, preventing IL-1 downstream signaling and activation of inflammation [104]. This change, however, was small and may not be relevant for the cell functionality. Further experiments will be conducted to better elucidate the cytokine findings described here.

Altogether, we consider PLA-NP a stealth nanomaterial in multicellular 3D human neural models, containing neuron and glial cells, without altering cell physiology and functionality and suitable for carrying drugs of interest in the CNS. In the future, we will address the cellspecific responses to the NP within the BrainSpheres such as reaction of glia cells (e.g., gliosis after exposure to AU-PEG, we observed in our preliminary data) . In addition, we will make use of our recently developed method of introducing microglia into the BrainSpheres [58]. This will allow us to look into the inflammatory response such as cytokine release by immune cells in more details.

\section{Conclusions}

This work showed that 3D brain spheroid models are well suited to comparatively characterize NP neurotoxicity. The simpler, single-cell model was more sensitive to the toxic effects, in line with the lack of glia support to neurons. The use of multiple models, which encompass simplicity and physiological relevance, serves as tool for more NP drug-delivery focused research (Fig. 9).

In conclusion, we have demonstrated that AuNP, the most used nanocarrier, as well as PLA-NP, may be harmful to pure dopaminergic neurons at the highest concentrations tested, which might represent a risk to contribute to Parkinson's disease development. In particular, in midbrain substantia nigra, where there is a high number of dopaminergic neurons, the use of nanocarriers should be carefully evaluated. However, this risk might be overestimated as the model lacks neuroprotection provided by astrocytes. Thus, BrainSpheres, are more appropriate model to study general neurotoxicity because they contain the glia, which can provide such neuronal support.

In a mixed population of neural cells within the BrainSpheres, the studied nanocarriers did not affect viability, likely due to the presence of glial cells and their participation in brain clearance. Our findings showed that AuNP promoted alterations in cell physiology that may contribute to increased susceptibility to other subsequent harmful agents in the CNS. Therefore, the use of AuNP as drug carrier in the CNS must be further evaluated. PLA-NP induced minor alterations in BrainSphere neural cell physiology, emerging as a safer alternative for brain drug delivery.

\section{Methods}

\section{Nanoparticles and chemicals}

Spherical monodisperse NP diluted in ultrapure water were used in this study. Au-SC were produced with $15 \mathrm{~nm}$ nominal diameter through reduction of $1 \%$ tetrachloroauric acid (Sigma Chem. Co.) by $1 \%$ sodium citrate aqueous solution (Merck KGaA), based on the Turkevich method revised by Kimling [105]. An Au-SC suspension was produced at $58 \mu \mathrm{g} / \mathrm{mL}$ and $1.7 \times 10^{12}$ particles $/ \mathrm{mL}$ concentration. Au-PEG 5-kDa at $1 \mathrm{mg} / \mathrm{mL}$ Au mass concentration $\left(10^{15}\right.$ particles $\left./ \mathrm{mL}\right)$ were purchased from Nanocomposix (batch JMW1410). Green-fluorescent Coumarin-6 PLA$\mathrm{NP}$ at $6.3 \mathrm{mg} / \mathrm{mL}$ polymer concentration $\left(1.05 \times 10^{13}\right.$ particles $/ \mathrm{mL}$ ) were acquired from IBCP (Lyon, France). All NP were stored and protected from light. Dimethyl sulfoxide (DMSO), paraformaldehyde (PFA) and cell lysis buffer (CelLytic M) were from Sigma Aldrich.

\section{Nanoparticle characterization}

NP were sonicated for $5 \mathrm{~min}$ and particle suspensions $(10 \mu \mathrm{L}$ of $1 \mu \mathrm{g} / \mathrm{mL})$ were deposited on copper grids, air- 


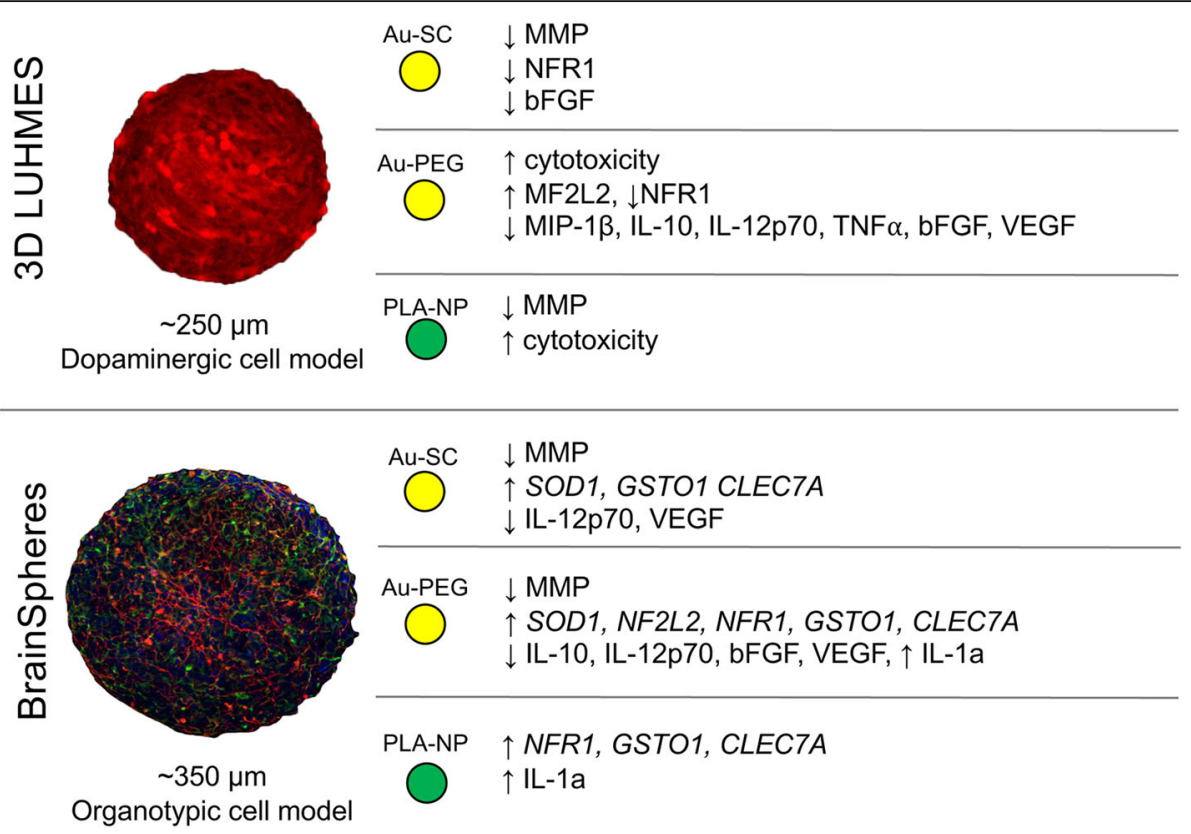

Fig. 9 Summary of the observed results in 3D LUHMES and 3D BrainSphere models exposed to the NP

dried and imaged in Tecnai G2 Spirit BioTwin 12 (AuSC and Au-PEG) or LEO 912 Omega (PLA-NP) (FEI) transmission electron microscopes (TEM), both operated at $120 \mathrm{kV}$. NP diameter size were determined by ImageJ software (https://imagej.nih.gov/ij/index.html $\mathrm{NIH})$. For analysis of NP hydrodynamic diameter, Au-SC $(6 \mu \mathrm{g} / \mathrm{mL}), A u-P E G$ and PLA-NP $(20 \mu \mathrm{g} / \mathrm{mL}$ each NP) were diluted in 3D LUHMES and BrainSpheres media and incubated in cell culture flasks without cells following the same conditions as for cell cultures. Then, $1 \mathrm{~mL}$ of sample was transferred to an appropriate cuvette for subsequent analysis of dynamic light scattering (DLS) in the Malvern Zetasizer Nano ZS apparatus (Malvern Instruments Ltd).

\section{Cell culture}

\section{D LUHMES}

Wild-type and red fluorescent protein (RFP) genetically modified LUHMES human neuronal precursor cells [106] were kindly provided by Prof. Marcel Leist (University of Konstanz) and maintained and cultured as previously described $[55,56,107]$. Briefly, flasks were precoated with $50 \mu \mathrm{g} / \mathrm{mL}$ poly-L-ornithine and $1 \mu \mathrm{g} / \mathrm{mL}$ fibronectin (both from Sigma Aldrich) for $12 \mathrm{~h}$. Cells were maintained in Advanced DMEM/F12 (ThermoFisher) supplemented with $2 \mathrm{mML}$-glutamine (Sigma Aldrich), 1x N2 (ThermoFisher) and $40 \mathrm{ng} / \mathrm{mL}$ recombinant basic Fibroblast Growth Factor (bFGF, R\&D Systems) (LUHMES proliferation medium), and passaged every 2-3 days. For 3D neuronal differentiation, cells were seeded in 6-well plates at $5 \times 10^{5}$ cells/well in $2 \mathrm{~mL}$
Advanced DMEM/F12 supplemented with $2 \mathrm{mM} \mathrm{L-glu-}$ tamine, $1 \mathrm{x}$ N2, $1 \mathrm{mM}$ dibutyryl cAMP (Santa Cruz), $2 \mu \mathrm{g} / \mathrm{mL}$ tetracycline (Sigma Aldrich) and $2 \mathrm{ng} / \mathrm{mL}$ recombinant human Glial cell line-Derived Neurotrophic Factor (GDNF, R\&D Systems) (LUHMES differentiation medium). The spheroids were placed on an orbital shaker (ES-X, Kuhner shaker) with $50 \mathrm{~mm}$ orbit diameter at $80 \mathrm{rpm}$ in a humidified incubator at $37^{\circ} \mathrm{C}$ and $10 \% \mathrm{CO}_{2}$. As per the differentiation protocol [107], paclitaxel (Sigma Aldrich) was added on day 3 to block proliferation and washed-out on day 5 . On day 7 , spheroid size was quantified using SPOT software 5.0 (Diagnostic Instruments Inc). 3D LUHMES were differentiated up to 10 days.

\section{BrainSpheres}

Neural progenitor cells (NPC) were differentiated from iPSC [108] and kindly provided by Professor Hongjun Song's lab within our joint project [54]. iPSC were derived from C1 (CRL-2097) fibroblasts purchased from ATCC [108]. NPC were maintained in KO DMEM/F12 medium supplemented with $1 \mathrm{x}$ StemPro supplement (ThermoFisher), $20 \mathrm{ng} / \mathrm{mL}$ human bFGF (ThermoFisher), $20 \mathrm{ng} / \mathrm{mL}$ Epidermal Growth Factor (EGF, ThermoFisher), $4 \mathrm{mM}$ L-Glutamine (ThermoFisher), 500 Units Penicillin and $500 \mu \mathrm{g}$ Streptomycin (ThermoFisher). Half of the medium was replaced every $24 \mathrm{~h}$. For BrainSpheres differentiation (previously described [54]), cells were mechanically detached when reached $100 \%$ confluence and seeded in 6-well plates at $2 \times 10^{6}$ cells in $2 \mathrm{~mL}$ Neurobasal Electro medium (ThermoFisher) 
supplemented with B-27-electro (ThermoFisher), $10 \mathrm{ng} /$ $\mathrm{mL}$ Brain-Derived Neurotrophic Factor (BDNF) and 10 ng/mL GDNF (Gemini), $4 \mathrm{mM} \mathrm{L-glutamine} \mathrm{(Thermo-}$ Fisher), 500 Units Penicillin, and $500 \mu \mathrm{g}$ Streptomycin (ThermoFisher). Cells were placed on an orbital shaker with $19 \mathrm{~mm}$ orbit diameter at $88 \mathrm{rpm}$ into humidified incubator at $37^{\circ} \mathrm{C}$ and $5 \% \mathrm{CO}_{2}$. Medium was replaced every $48 \mathrm{~h}$. After 4 weeks of differentiation, the BrainSpheres were used for the experiments. Spheroid size was quantified using SPOT software 5.0 (Diagnostic Instruments, Inc.).

\section{NP treatment}

NP stock suspensions were diluted in differentiation media on the day of treatment to prepare following final concentrations: $0.06,0.6$ and $6 \mu \mathrm{g} / \mathrm{mL}$ of Au-SC; 0.2, 2 and $20 \mu \mathrm{g} / \mathrm{mL}$ of Au-PEG and PLA nanoparticles. The used $\mathrm{Au}$ mass concentrations were in the range of previous in vitro studies [75-77]. 3D LUHMES were treated with NP on day 7 of differentiation for 24 or $72 \mathrm{~h}$. BrainSpheres were treated with NP after 4 weeks of differentiation for 24 or $72 \mathrm{~h}$. Then, spheroid and supernatant samples were collected for endpoint measurements.

\section{Immunocytochemistry and confocal microscopy}

3D cultures were fixed with $4 \%$ paraformaldehyde (PFA) for $1 \mathrm{~h}$, washed 3 times with PBS and incubated for $2 \mathrm{~h}$ with blocking buffer (1\% BSA, 5\% goat serum, $0.15 \%$ saponin (Sigma Aldrich)). Samples were incubated $48 \mathrm{~h}$ with primary antibodies (1:200 mouse anti-MAP2 (Sigma Aldrich); 1:200 rabbit anti-GFAP (Dako) and 1: 200 mouse anti-Olig1 (Millipore), 1:200 mouse antiSynaptophysin (Sigma), 1:200 rabbit anti-PSD95 (Life Technologies), 1:1500 $\beta$-III-tubulin (Sigma Aldrich), 1: 200 anti O4 (R\&D Systems) diluted in blocking buffer) at $4{ }^{\circ} \mathrm{C}$, followed by three washing steps and incubation with secondary antibodies (1:500 goat anti-mouse Alexa fluor 488 or 1:500 goat anti-rabbit Alexa fluor 568, diluted in blocking buffer, Molecular Probes) overnight. Then, samples were washed and incubated with Hoechst 33342 (1:10,000, Molecular Probes) for at least $1 \mathrm{~h}$ at room temperature (RT). After three washing steps, the samples were mounted on glass slides with Prolong Gold-antifade reagent (Molecular Probes) for confocal microscopy. Z-stacks started at the top of the sample were taking. Images were obtained with Zeiss LSM-510 (Zeiss) and Leica SP5 (Leica) confocal microscopes with identical time exposure and image settings.

\section{Flow cytometry}

3D RFP-expressing LUHMES treated with different concentrations of PLA-NP for $24 \mathrm{~h}$ or $72 \mathrm{~h}$ were trypsinized with TryplE Express containing 4 units/mL DNase at $37^{\circ} \mathrm{C}$ for $30 \mathrm{~min}$ on the shaker. $40 \mu \mathrm{g} / \mathrm{mL}$ Trypan Blue was added to subset of the samples to quench NP fluorescence from outside the cells. Then, samples were homogenized using a $1 \mathrm{~mL}$ syringe with a 26G3/8 needle. Cells were washed with PBS twice, fixed with 4\% PFA for $30 \mathrm{~min}$ and the co-localization between 3D RPFexpressing LUHMES cells and PLA-NP green fluorescence was quantified using a FACSCalibur flow cytometer (BD) or with ImageStreamX Mark II imaging flow cytometer (Amnis) (in this case cells were imaged live). The instrument was calibrated using fluorescent beads and wild-type LUHMES cells were used as negative control to set the gates.

\section{Inductively coupled plasma mass spectrometry (ICP-MS)}

AuNP stock solution was used to prepare the calibration solutions through serial aqueous dilutions for ICP-MS determination (NexION 300D, PerkinElmer). 1\% (v/v) nitric acid (Merck) and $10 \mu \mathrm{g} / \mathrm{L}$ rhodium from PerkinElmer was added to the calibration solution, blank, and samples to improve analytical performance. The $\mathrm{Au}^{197}$ isotope was measured. For quantification of intracellular $\mathrm{Au}$ mass, spheroids of both models were treated for 24 or $72 \mathrm{~h}$ with $\mathrm{Au}-\mathrm{SC}$ or Au-PEG. Then, spheroids were collected and lysed (CelLytic M lysis buffer, Molecular Probes) for analysis.

\section{Mitochondrial membrane potential assay}

After NP treatment, mitochondrial membrane potential $(\triangle \Psi \mathrm{m}, \mathrm{MMP})$ was analyzed using MitoTracker ${ }^{\circ}$ Red CMXRos (ThermoFisher), according to manufacturer's recommendations. After 45 min treatment with MitoTracker Red CMXRos reagent, spheroids were fixed with 4\% PFA for $1 \mathrm{~h}$ at RT, washed with PBS and mounted on glass slides. Images were acquired with fluorescence microscope (Olympus BX60) and red fluorescence intensity was quantified by ImageJ software (https://imagej. nih.gov/ij/index.html, NIH).

\section{Lactate dehydrogenase (LDH) release assay}

LDH release was determined by colorimetric CytoTox 96 Cytotoxicity Assay kit (Promega). As positive control, spheroids were treated with $1 \%$ TX-100 for $30 \mathrm{~min}$. After NP treatments, $20 \mu \mathrm{L}$ of supernatants were transferred to 96 -well plates followed by the addition of $20 \mu \mathrm{L}$ of substrate solution. After $30 \mathrm{~min}$ of incubation in the dark at $\mathrm{RT}, 20 \mu \mathrm{L}$ of stop solution was added to each sample. Color development was proportional to the number of cells with disruption of plasma membrane. Absorbance was measured at $490 \mathrm{~nm}$. For evaluation of eventual colorimetric interference, NP diluted in culture medium were incubated with LDH positive control and substrate according to manufacturer's instructions. 
Scanning electron microscopy (SEM)

Spheroids were fixed with $2.5 \%$ glutaraldehyde for $1 \mathrm{~h}$ at RT. After three washing steps with PBS, samples were postfixed with $1 \%$ osmium tetroxide for $90 \mathrm{~min}$ in the dark, followed by three washing steps with $0.1 \mathrm{M}$ cacodilate buffer $(\mathrm{pH} 7.4)$ and distilled water. Samples were gradually dehydrated, dried at the critical-point and finally vaporized with platinum. Photomicrographs were obtained at $3 \mathrm{kV}$ in a SEM Helios Nanolab 650 (FEI, ThermoFisher).

\section{RNA extraction and quantitative real-time polymerase chain reaction ( $q R T-P C R$ )}

Total RNA was extracted from 3D cultures after NP treatments using Tripure isolation reagent (Roche) according to Chomczynski and Sacchi [109]. RNA quantity and purity was determined using NanoDrop 2000c (ThermoFisher). One microgram of RNA was reversetranscribed using the M-MLV Promega Reverse Transcriptase (Promega) according to the manufacturer's recommendations. The expression of genes was evaluated using specific TaqMan gene expression assays (ThermoFisher). qRT-PCRs were performed using a 7500 Fast Real Time system (Applied Biosystems). Relative mRNA expression was calculated using the $2^{-\Delta \Delta \mathrm{Ct}}$ method [110]. The analyzed genes were: SOD1 (Hs00533490_ m1), NF2L2 (Hs00975961_g1), NFR1 (Hs00602161_m1), GSTO1 (Hs02383465_s1), CLEC7A (Hs01902549) and SOD2 (Hs00167309_m1). $\beta$-actin (BrainSpheres) and $18 \mathrm{~S}$ (LUHMES) were used as housekeeping gene.

\section{Analysis of multiple secreted mediators}

Determination of cytokines, chemokines and growth factors secreted by 3D LUHMES and BrainSpheres cultures upon NP exposure was carried through Luminex (Austin TX, USA) xMAP magnetic technology for the following analytes: IL-1 $\beta$, IL-1ra, IL-2, IL-4, IL-5, IL-6, IL-7, IL-8, IL-9, IL-10, IL-12 (p70), IL-13, IL-15, IL-17, eotaxin, bFGF, GCSF, GM-CSF, IFN- $\gamma$, IP-10, MCP-1 (MCAF), MIP- $1 \alpha$, MIP- $1 \beta$, PDGF-BB, RANTES, TNF $\alpha$ and VEGF, and TGF- $\beta 1$, TGF- $\beta 2$ and TGF- $\beta 3$. Analysis was performed following the manufacturer's recommendations. Briefly, after calibration and validation of Bio-Plex Magpix (Bio-Rad), reagent reconstitution and standard curve preparation, magnetic beads were added to each well of the assay plate. Each step was preceded by washing steps using an automated Bio-Plex Pro wash station (Bio-Rad). Then, samples, standard and controls were added, followed by detection antibodies and streptavidin-PE. Finally, magnetic beads were re-suspended and read. The number of analytes detected in culture medium without spheres (background) was subtracted from the samples, allowing to access the protein levels secreted by cultures.

\section{Additional files}

Additional file 1: Z-stack from RFP-LUHMES treated with PLA NP, demonstrating internalization of NP. (GIF $4019 \mathrm{~kb}$ )

Additional file 2: $3 \mathrm{D}$ reconstruction of additional file 1 demonstrating internalization of PLA NP in RFP-LUHMES model. (GIF $4152 \mathrm{~kb}$ )

Additional file 3: Figure S1. Flow cytometry analysis of RFP-LUHMES exposed to PLA NP. (A) Dot plots of 3D LUHMES exposed to 0.2, 2 and $20 \mu \mathrm{g} / \mathrm{mL}$ PLA NP. Wild type LUHMES were used to set up the gates. (B) and $(C)$ image galleries generated by ImageStream $X$ Marc II flow cytometer from untreated RFP-LUHMES and RFP-LUHMES treated with $20 \mu \mathrm{g} / \mathrm{mL}$ PLA respectively. Ch01 - phase contrast, Ch02 - green, Ch04 red and Ch06- site scater. (D) Histogram of green fluorescence intensity in untreated RFP-LUHMES (red), RFP-LUHMES treated with $20 \mu \mathrm{g} / \mathrm{mL}$ PLA (green) and RFP-LUHMES treated with $20 \mu \mathrm{g} / \mathrm{mL}$ PLA and subsequently with $40 \mu \mathrm{g} / \mathrm{mL}$ of trypan blue (blue). Table shows the number of live cells gated in each sample and median of the fluorescence intensity in each sample. (TIF 1877 kb)

Additional file 4: Figure S2. Effect of NP on expression of genes related to ROS regulation in $3 D$ LUHMES. Graphs showing the relative expression of SOD1, NF2L2, NFR1, GSTO1 and SOD2 after exposure to AuSC $(6 \mu \mathrm{g} / \mathrm{mL})$, Au-PEG $(20 \mu \mathrm{g} / \mathrm{mL})$ and PLA-NP $(20 \mu \mathrm{g} / \mathrm{mL})$ for $72 \mathrm{~h}$ normalized to the expression of the genes in the untreated control spheroids. Data was collected from two independent experiments with total eight biological replicates and represents fold changes (FC \pm SEM). Only four replicates were used for Au-SC treated samples. One-way ANOVA with Dunnett's multiple comparisons post-test was used to analyze the statistical significance. (TIF $86 \mathrm{~kb}$ )

Additional file 5: Figure S3. Influence of NP on release of TGF- $\beta$ isoforms in 3D LUHMES. Graphs show the levels of secreted TGF- $\beta 1$, TGF- $\beta 2$ and TGF- $\beta 3$ after exposure to Au-SC $(6 \mu \mathrm{g} / \mathrm{mL})$, Au-PEG $(20 \mu \mathrm{g} / \mathrm{mL})$ and PLA-NP $(20 \mu \mathrm{g} / \mathrm{mL})$ for 24 and $72 \mathrm{~h}$ in comparison to the untreated control spheroids. Each experimental group corresponds to the analysis of three independent experiments with three replicates and represents mean ( \pm SEM). (TIF $3028 \mathrm{~kb}$ )

\section{Acknowledgments}

We are very grateful for MSc. Vania da Silva Vieira for the essential assistance in scanning electron microscope, and Dr. Emile Santos Barrias, for the valuable assistance in fluorescence confocal microscope for image acquisition of Fig. 3, both from INMETRO. We acknowledge the excellent assistance with flow cytometry experiments from Bloomberg Flow Cytometry and Immunology core and in particularly Tricia Nilles.

\section{Authors' contributions}

MRP, GH, LS performed experimental work in 3D LUHMES model. PECL, DP performed experimental work in 3D BrainSpheres. PECL, GH and LS wrote the manuscript. GH and LS developed 3D LUHMES model. LMdS performed the ICP-MS the experiments of inductively coupled plasma mass spectrometry. HTH, DP and TH developed 3D Brainsphere model. JMG supervised work on nanoparticle characterization. LS coordinated the project. All authors read and approved the final manuscript.

\section{Funding}

This study was supported by the Coordenação de Aperfeiçoamento de Pessoal de Nível Superior - Brasil (CAPES) - Finance Code 001, FAPERJ (Fundação de Amparo à Pesquisa do Rio de Janeiro), CNPQ (Conselho Nacional de Desenvolvimento Científco e Tecnológico), and PRONAMETRO fellowship program (Programa de Apoio ao Desenvolvimento da Metrologia, Qualidade e Tecnologia) of INMETRO. Funding bodies were not involved in study design, data collection, analysis, interpretation, or writing of the manuscript.

\section{Availability of data and materials}

The datasets used and/or analyzed during the current study are available from the corresponding author on reasonable request. 


\section{Consent for publication}

$\mathrm{N} / \mathrm{A}$

\section{Competing interests}

The authors declare that they have no competing interests.

\section{Author details}

${ }^{1}$ Directory of Metrology Applied to Life Sciences - Dimav, National Institute of Metrology Quality and Technology - INMETRO, Av. Nossa Senhora das Graças 50, LABET - Dimav, Predio 27, Duque de Caxias, Xerem, Rio de Janeiro 25250-020, Brazil. Biology Institute, Fluminense Federal University, Niteroi, Rio de Janeiro, Brazil. ${ }^{3}$ Center for Alternatives to Animal Testing (CAAT), Bloomberg School of Public Health, Johns Hopkins University, 615 N. Wolfe Street, Baltimore, MD 21205, USA. ${ }^{4}$ Department of Chemistry, National Institute of Quality Control in Health - INCQS/Fiocruz, Manguinhos, Rio de Janeiro 21040-900, Brazil. ' University of Konstanz, Biology, Konstanz, Germany. ${ }^{6}$ Dental School, Fluminense Federal University, Niteroi, Rio de Janeiro, USA. ${ }^{7}$ Department of Physiology, University of Lausanne, Lausanne $\mathrm{CH}-1015$, USA

\section{Received: 6 November 2018 Accepted: 21 May 2019} Published online: 03 June 2019

\section{References}

1. Wu T, Tang M. Review of the effects of manufactured nanoparticles on mammalian target organs. J Appl Toxicol. 2017;38(1):25-40. Available from: http://www.ncbi.nlm.nih.gov/pubmed/28799656.

2. Zhang XD, Wu D, Shen X, Liu PX, Yang N, Zhao B, et al. Size-dependent in vivo toxicity of PEG-coated gold nanoparticles. Int J Nanomedicine. 2011;6: 2071-81. Available from: http://www.ncbi.nlm.nih.gov/pubmed/21976982.

3. Leite PEC, Pereira MR, Granjeiro JM. Hazard effects of nanoparticles in central nervous system: searching for biocompatible nanomaterials for drug delivery. Toxicol in Vitro. 2015;29(7):1653-60. Available from: https://www. ncbi.nlm.nih.gov/pubmed/26116398.

4. Bhaskar S, Tian F, Stoeger T, Kreyling W, de la Fuente JM, Grazu V, et al. Multifunctional Nanocarriers for diagnostics, drug delivery and targeted treatment across blood-brain barrier: perspectives on tracking and neuroimaging. Part Fibre Toxicol. 2010;7:3. Available from: http://www.ncbi. nlm.nih.gov/pubmed/20199661.

5. Zhou Y, Peng Z, Seven ES, Leblanc RM. Crossing the blood-brain barrier with nanoparticles. J Control Release. 2018;270:290-303 Available from: http://www.ncbi.nlm.nih.gov/pubmed/29269142.

6. D'Agata F, Ruffinatti FA, Boschi S, Stura I, Rainero I, Abollino O, et al. Magnetic nanoparticles in the central nervous system: targeting principles, applications and safety issues. Molecules. 2017;23(1):9. Available from: http://www.ncbi.nlm.nih.gov/pubmed/29267188

7. Patel MM, Patel BM. Crossing the blood-brain barrier: recent advances in drug delivery to the brain. CNS Drugs. 2017:31(2):109-33. Available from: http://www.ncbi.nlm.nih.gov/pubmed/28101766.

8. Carradori D, Gaudin A, Brambilla D, Andrieux K. Application of nanomedicine to the CNS diseases. Int Rev Neurobiol. 2016;130:73-113 Available from: http://www.ncbi.nlm.nih.gov/pubmed/27678175.

9. Zhang G, Yang Z, Lu W, Zhang R, Huang Q, Tian M, et al. Influence of anchoring ligands and particle size on the colloidal stability and in vivo biodistribution of polyethylene glycol-coated gold nanoparticles in tumorxenografted mice. Biomaterials. 2009;30(10):1928-36. Available from: https:// www.ncbi.n/m.nih.gov/pubmed/19131103.

10. Oh E, Delehanty JB, Sapsford KE, Susumu K, Goswami R, Blanco-Canosa JB, et al. Cellular uptake and fate of PEGylated gold nanoparticles is dependent on both cell-penetration peptides and particle size. ACS Nano. 2011;5(8): 6434-48. Available from: https://www.ncbi.nlm.nih.gov/pubmed/21774456.

11. Schaeublin NM, Braydich-Stolle LK, Maurer El, Park K, MacCuspie Rl, Afrooz ARMN, et al. Does shape matter? Bioeffects of gold nanomaterials in a human skin cell model. Langmuir. 2012;28(6):3248-58. Available from: https://www.ncbi.nlm.nih.gov/pubmed/22242624.

12. Gao K, Jiang $X$. Influence of particle size on transport of methotrexate across blood brain barrier by polysorbate 80-coated polybutylcyanoacrylate nanoparticles. Int J Pharm. 2006;310(1-2):213-9. Available from: https://www. ncbi.nlm.nih.gov/pubmed/16426779.

13. Betzer O, Shilo M, Opochinsky R, Barnoy E, Motiei M, Okun E, et al. The effect of nanoparticle size on the ability to cross the blood-brain barrier: an in vivo study. Nanomedicine. 2017;12(13):1533-46. Available from: https:// www.ncbi.nlm.nih.gov/pubmed/28621578.

14. Yue ZG, Wei W, Lv PP, Yue H, Wang LY, Su ZG. et al., Surface charge affects cellular uptake and intracellular trafficking of chitosan-based nanoparticles. Biomacromolecules. 2011;12(7):2440-6. Available from: https://www.ncbi.nlm. nih.gov/pubmed/21657799.

15. Dinda SC, Pattnaik G. Nanobiotechnology-based drug delivery in brain targeting. Curr Pharm Biotechnol. 2013;14(15):1264-74. Available from: http://www.ncbi.n/m.nih.gov/pubmed/24910011

16. Cheng $Y$, Morshed RA, Auffinger B, Tobias AL, Lesniak MS. Multifunctional nanoparticles for brain tumor imaging and therapy. Adv Drug Deliv Rev. 2014;66:42-57 Available from: http://www.ncbi.nlm.nih.gov/pubmed/ 24060923.

17. Tam VH, Sosa C, Liu R, Yao N, Priestley RD. Nanomedicine as a non-invasive strategy for drug delivery across the blood brain barrier. Int J Pharm. 2016;515(12):331-42. Available from: http://www.ncbi.nlm.nih.gov/pubmed/27769885 .

18. Delgado-Buenrostro NL, Medina-Reyes El, Lastres-Becker I, Freyre-Fonseca V, Ji Z, Hernandez-Pando R, et al. Nrf2 protects the lung against inflammation induced by titanium dioxide nanoparticles: a positive regulator role of Nrf2 on cytokine release. Environ Toxicol. 2015;30(7):782-92. Available from: http://www.ncbi.n/m.nih.gov/pubmed/24615891.

19. Li JJ, Hartono D, Ong CN, Bay BH, Yung LY. Autophagy and oxidative stress associated with gold nanoparticles. Biomaterials. 2010;31(23):5996-6003. Available from: http://www.ncbi.nlm.nih.gov/pubmed/20466420.

20. Hartung T, Sabbioni E. Alternative in vitro assays in nanomaterial toxicology Wiley Interdiscip Rev Nanomed Nanobiotechnol. 2011;3(6):545-73. Available from: http://www.ncbi.nlm.nih.gov/pubmed/21766468

21. Mushtaq G, Khan JA, Joseph E, Kamal MA. Nanoparticles, neurotoxicity and neurodegenerative diseases. Curr Drug Metab. 2015;16(8):676-84. Available from: http://www.ncbi.nlm.nih.gov/pubmed/26264205.

22. Nicolardi S, van der Burgt YEM, Codee JDC, Wuhrer M, Hokke $\mathrm{CH}$, Chiodo F. Structural characterization of biofunctionalized gold nanoparticles by ultrahigh-resolution mass spectrometry. ACS Nano. 2017;11(8):8257-64. Available from: http://www.ncbi.nlm.nih.gov/pubmed/28686409.

23. Chueh PJ, Liang RY, Lee YH, Zeng ZM, Chuang SM. Differential cytotoxic effects of gold nanoparticles in different mammalian cell lines. J Hazard Mater. 2014;264:303-12 Available from: http://www.ncbi.nlm.nih.gov/ pubmed/24316248.

24. Leite PEC, Pereira MR, Santos CADN, Campos APC, Esteves TM, Granjeiro JM. Gold nanoparticles do not induce myotube cytotoxicity but increase the susceptibility to cell death. Toxicol in Vitro. 2015;29(5):819-27. Available from: https://www.ncbi.nlm.nih.gov/pubmed/25790728.

25. Engin $A B$, Nikitovic $D$, Neagu M, Henrich-Noack $P$, Docea $A O$, Shtilman MI, et al. Mechanistic understanding of nanoparticles' interactions with extracellular matrix: the cell and immune system. Part Fibre Toxicol. 2017; 14(1):22. Available from: http://www.ncbi.nlm.nih.gov/pubmed/28646905

26. Tosi G, Vergoni AV, Ruozi B, Bondioli L, Badiali L, Rivasi F, et al. Sialic acid and glycopeptides conjugated PLGA nanoparticles for central nervous system targeting: in vivo pharmacological evidence and biodistribution. J Control Release. 2010;145(1):49-57. Available from: http://www.ncbi.nlm.nih. gov/pubmed/20338201

27. Trif M, Florian PE, Roseanu A, Moisei M, Craciunescu O, Astete CE, et al. Cytotoxicity and intracellular fate of PLGA and chitosan-coated PLGA nanoparticles in Madin-Darby bovine kidney (MDBK) and human colorectal adenocarcinoma (Colo 205) cells. J Biomed Mater Res A. 2015;103(11):3599611. Available from: http://www.ncbi.nlm.nih.gov/pubmed/25976509

28. Vasir JK, Labhasetwar V. Biodegradable nanoparticles for cytosolic delivery of therapeutics. Adv Drug Deliv Rev. 2007:59(8):718-28. Available from: http:// www.ncbi.nlm.nih.gov/pubmed/17683826.

29. Pamies D, Hartung T. 21st century cell culture for 21st century toxicology. Chem Res Toxicol. 2017;30(1):43-52. Available from: http://www.ncbi.nlm. nih.gov/pubmed/28092941.

30. Pamies D, Hartung T, Hogberg HT. Biological and medical applications of a brain-on-a-chip. Exp Biol Med. 2014;239(9):1096-107. Available from: http:// www.ncbi.nlm.nih.gov/pubmed/24912505.

31. Alepee N, Bahinski A, Daneshian M, De Wever B, Fritsche E, Goldberg A, et al. State-of-the-art of 3D cultures (organs-on-a-chip) in safety testing and pathophysiology. ALTEX. 2014;31(4):441-77. Available from: http://www. ncbi.nlm.nih.gov/pubmed/25027500

32. Hartung T. 3D - a new dimension of in vitro research. Adv Drug Deliv Rev. 2014,vi:69-70 Available from: http://www.ncbi.nlm.nih.gov/pubmed/24721291. 
33. Marx U, Andersson TB, Bahinski A, Beilmann M, Beken S, Cassee FR, et al. Biology-inspired microphysiological system approaches to solve the prediction dilemma of substance testing. ALTEX. 2016;33(3):272-321. Available from: http://www.ncbi.nlm.nih.gov/pubmed/27180100.

34. Jurga M, Lipkowski AW, Lukomska B, Buzanska L, Kurzepa K, Sobanski T, et al. Generation of functional neural artificial tissue from human umbilical cord blood stem cells. Tissue Eng Part C Methods. 2009;15(3):365-72. Available from: http://www.ncbi.nlm.nih.gov/pubmed/19719393.

35. Bhise NS, Gray RS, Sunshine JC, Htet S, Ewald AJ, Green JJ. The relationship between terminal functionalization and molecular weight of a gene delivery polymer and transfection efficacy in mammary epithelial 2-D cultures and 3-D organotypic cultures. Biomaterials. 2010;31(31):8088-96. Available from: http://www.ncbi.nlm.nih.gov/pubmed/20674001.

36. Gibb S. Toxicity testing in the 21st century: a vision and a strategy. Reprod Toxicol. 2008;25(1):136-8. Available from: http://www.ncbi.nlm.nih.gov/ pubmed/18093799.

37. Bhise NS, Ribas J, Manoharan V, Zhang YS, Polini A, Massa S, et al. Organ-ona-chip platforms for studying drug delivery systems. J Control Release. 2014; 190:82-93 Available from: http://www.ncbi.n/m.nih.gov/pubmed/24818770.

38. Choi JH, Lee J, Shin W, Choi JW, Kim HJ. Priming nanoparticle-guided diagnostics and therapeutics towards human organs-on-chips microphysiological system. Nano Converg. 2016;3(1):24. Available from: http://www.ncbi.nlm.nih.gov/pubmed/28191434

39. Goodman TT, Ng CP, Pun SH. 3-D tissue culture systems for the evaluation and optimization of nanoparticle-based drug carriers. Bioconjug Chem. 2008;19(10): 1951-9. Available from: http://www.ncbi.nlm.nih.gov/pubmed/18788773.

40. Lee J, Lilly GD, Doty RC, Podsiadlo P, Kotov NA. In vitro toxicity testing of nanoparticles in 3D cell culture. Small. 2009;5(10):1213-21. Available from: http://www.ncbi.nlm.nih.gov/pubmed/19263430.

41. Sreekanthreddy P, Gromnicova R, Davies H, Phillips J, Romero IA, Male D. A three-dimensional model of the human blood-brain barrier to analyse the transport of nanoparticles and astrocyte/endothelial interactions. F1000Res. 2015;4:1279 Available from: http://www.ncbi.nlm.nih.gov/pubmed/26870320.

42. Hoelting L, Scheinhardt B, Bondarenko O, Schildknecht S, Kapitza M, Tanavde V, et al. A 3-dimensional human embryonic stem cell (hESC)derived model to detect developmental neurotoxicity of nanoparticles. Arch Toxicol. 2013;87(4):721-33. Available from: http://www.ncbi.nlm.nih.gov/ pubmed/23203475

43. Zeng Y, Kurokawa Y, Zeng Q, Win-Shwe T, Nansai H, Zhang Z, et al. Effects of Polyamidoamine dendrimers on a 3-D Neurosphere system using human neural progenitor cells. Toxicol Sci. 2016;152(1):128-44. Available from: http://www.ncbi.nlm.nih.gov/pubmed/27125967

44. Hartung T. Food for thought ... on alternative methods for nanoparticle safety testing. ALTEX. 2010;27(2):87-95. Available from: http://www.ncbi. nlm.nih.gov/pubmed/20686741

45. Silbergeld EK, Contreras EQ, Hartung T, Hirsch C, Hogberg H, Jachak AC, et al. t (4) workshop report. Nanotoxicology: "the end of the beginning" - signs on the roadmap to a strategy for assuring the safe application and use of nanomaterials. ALTEX. 2011;28(3):236-41. Available from: http://www.ncbi. nlm.nih.gov/pubmed/21993959.

46. Kim JH, Kim JH, Kim KW, Kim MH, Yu YS. Intravenously administered gold nanoparticles pass through the blood-retinal barrier depending on the particle size, and induce no retinal toxicity. Nanotechnology. 2009;20(50): 505101. Available from: https://www.ncbi.nlm.nih.gov/pubmed/19923650.

47. El-Drieny EEA, Sarhan N, Bayomy N, Elmajied Elsherbeni S, Momtaz R, Mohamed H-D. Histological and immunohistochemical study of the effect of gold nanoparticles on the brain of adult male albino rat. J Microsc Ultrastruct. 2015;3(4):181-90. Available from: https://www.ncbi.nIm.nih.gov/ pmc/articles/PMC6014274/.

48. Bejjani RA, BenEzra D, Cohen H, Rieger J, Andrieu C, Jeanny J-C, et al. Nanoparticles for gene delivery to retinal pigment epithelial cells. Mol Vis. 2005;11:124-32. Available from: https://www.ncbi.nlm.nih.gov/pubmed/ 15735602.

49. Hayashi A, Naseri A, Pennesi ME, De Juan E. Subretinal delivery of immunoglobulin $\mathrm{G}$ with gold nanoparticles in the rabbit eye. Jpn J Ophthalmol. 2009;53(3):249-56. Available from: https://www.ncbi.nlm.nih. gov/pubmed/19484444.

50. Wang $Y T$, Lu XM, Zhu F, Huang $P, Y u$ Y, Zeng $L$, et al. The use of a gold nanoparticle-based adjuvant to improve the therapeutic efficacy of hNgR-Fc protein immunization in spinal cord-injured rats. Biomaterials. 2011;32(31): 7988-98. Available from: https://www.ncbi.nlm.nih.gov/pubmed/21784510.
51. Pavot V, Rochereau N, Primard C, Genin C, Perouzel E, Lioux T, et al. Encapsulation of Nod1 and Nod2 receptor ligands into poly (lactic acid) nanoparticles potentiates their immune properties. J Control Release. 2013; 167(1):60-7. Available from: http://www.ncbi.n/m.nih.gov/pubmed/23352911 .

52. Climent N, Munier S, Piqué N, García F, Pavot V, Primard C, et al. Loading dendritic cells with PLA-p24 nanoparticles or MVA expressing HIV genes induces HIV-1-specific T cell responses. Vaccine. 2014; 32(47):6266-76. Available from: https://www.ncbi.nlm.nih.gov/pubmed/25240755.

53. Horie RT, Sakamoto T, Nakagawa T, Ishihara T, Higaki M, Ito J. Stealthnanoparticle strategy for enhancing the efficacy of steroids in mice with noise-induced hearing loss. Nanomedicine (Lond). 2010;5(9):1331-40. Available from: http://www.ncbi.nlm.nih.gov/pubmed/21128717.

54. Pamies D, Barreras P, Block K, Makri G, Kumar A, Wiersma D, et al. A human brain microphysiological system derived from induced pluripotent stem cells to study neurological diseases and toxicity. ALTEX. 2017;34(3):362-76. Available from: http://www.ncbi.nlm.nih.gov/pubmed/27883356

55. Scholz D, Poltl D, Genewsky A, Weng M, Waldmann T, Schildknecht S, et al. Rapid, complete and large-scale generation of post-mitotic neurons from the human LUHMES cell line. J Neurochem. 2011;119(5):957-71. Available from: http://www.ncbi.nlm.nih.gov/pubmed/21434924 .

56. Smirnova L, Harris G, Delp J, Valadares M, Pamies D, Hogberg HT, et al. A LUHMES 3D dopaminergic neuronal model for neurotoxicity testing allowing long-term exposure and cellular resilience analysis. Arch Toxicol. 2016;90(11): 2725-43. Available from: http://www.ncbi.nlm.nih.gov/pubmed/26647301.

57. Hogberg HT, Bressler J, Christian KM, Harris G, Makri G, O’Driscoll C, et al. Toward a 3D model of human brain development for studying gene/ environment interactions. Stem Cell Res Ther. 2013;4(Suppl 1):S4 Available from: http://www.ncbi.nlm.nih.gov/pubmed/24564953.

58. Abreu CM, Gama L, Krasemann S, Chesnut M, Odwin-Dacosta S, Hogberg $H T$. et al., Microglia increase inflammatory responses in iPSC-Derived Human BrainSpheres. Front Microbiol. 2018;9:2766. Available from: https://www.ncbi. nlm.nih.gov/pubmed/30619100.

59. Plummer S, Wallace S, Ball G, Lloyd R, Schiapparelli P, Quiñones-Hinojosa A, et al. A human iPSC-derived 3D platform using primary brain cancer cells to study drug development and personalized medicine. Sci Rep. 2019;9(1): 1407. Available from: https://www.ncbi.nlm.nih.gov/pmc/articles/ PMC6363784/.

60. Zander NE, Piehler T, Hogberg H, Pamies D. Explosive blast loading on human 3D aggregate Minibrains. Cell Mol Neurobiol. 2017;37(7):1331-4. Available from: https://www.ncbi.nlm.nih.gov/pubmed/28110483.

61. Arnida MA, Ghandehari H. Cellular uptake and toxicity of gold nanoparticles in prostate cancer cells: a comparative study of rods and spheres. J Appl Toxicol. 2010;30(3):212-7. Available from: http://www.ncbi.nlm.nih.gov/ pubmed/19902477

62. Drasler B, Vanhecke D, Rodriguez-Lorenzo L, Petri-Fink A, Rothen-Rutishauser B. Quantifying nanoparticle cellular uptake: which method is best? Nanomedicine (Lond). 2017;12(10):1095-9. Available from: http://www.ncbi. nlm.nih.gov/pubmed/28447906 .

63. Hsiao IL, Bierkandt FS, Reichardt P, Luch A, Huang YJ, Jakubowski N, et al. Quantification and visualization of cellular uptake of $\mathrm{TiO} 2$ and ag nanoparticles: comparison of different ICP-MS techniques. J Nanobiotechnol. 2016;14(1):50. Available from: http://www.ncbi.nlm.nih. gov/pubmed/27334629

64. Collins AR, Annangi B, Rubio L, Marcos R, Dorn M, Merker C, et al. High throughput toxicity screening and intracellular detection of nanomaterials. Wiley Interdiscip Rev Nanomed Nanobiotechnol. 2017;9(1). Available from: https://www.ncbi.nlm.nih.gov/pubmed/27273980.

65. Kessel D. Reversible effects of photodamage directed toward mitochondria. Photochem Photobiol. 2014;90(5):1211-3. Available from: http://www.ncbi. nlm.nih.gov/pubmed/24762128.

66. Nicholls DG, Ward MW. Mitochondrial membrane potential and neuronal glutamate excitotoxicity: mortality and millivolts. Trends Neurosci. 2000; 23(4):166-74. Available from: http://www.ncbi.nlm.nih.gov/pubmed/ 10717676 .

67. Huser J, Blatter LA. Fluctuations in mitochondrial membrane potential caused by repetitive gating of the permeability transition pore. Biochem J. 1999;343(Pt 2):311-7 Available from: http://www.ncbi.nlm.nih.gov/pubmed/ 10510294.

68. Galic MA, Riazi K, Pittman QJ. Cytokines and brain excitability. Front Neuroendocrinol. 2012;33(1):116-25. Available from: http://www.ncbi.nlm. nih.gov/pubmed/22214786 . 
69. Acharya S, Hill RA. High efficacy gold-KDEL peptide-siRNA nanoconstructmediated transfection in C2C12 myoblasts and myotubes. Nanomedicine. 2014 10(2):329-37. Available from: http://www.ncbi.nlm.nih.gov/pubmed/23928216.

70. Noh SM, Kim WK, Kim SJ, Kim JM, Baek KH, Oh YK. Enhanced cellular delivery and transfection efficiency of plasmid DNA using positively charged biocompatible colloidal gold nanoparticles. Biochim Biophys Acta. 2007;1770(5):747-52. Available from: http://www.ncbi.nlm.nih.gov/pubmed/17324519

71. Liu Z, Gao X, Kang T, Jiang M, Miao D, Gu G, et al. B6 peptide-modified PEGPLA nanoparticles for enhanced brain delivery of neuroprotective peptide. Bioconjug Chem. 2013;24(6):997-1007. Available from: http://www.ncbi.nlm. nih.gov/pubmed/23718945

72. Tsou YH, Zhang XQ, Zhu H, Syed S, Xu X. Drug delivery to the brain across the blood-brain barrier using nanomaterials. Small. 2017;13(43). Available from: http://www.ncbi.nlm.nih.gov/pubmed/29045030

73. Kong FY, Zhang JW, Li RF, Wang ZX, Wang WJ, Wang W. Unique roles of gold nanoparticles in drug delivery, targeting and imaging applications. Molecules. 2017;22(9):1445. Available from: http://www.ncbi.nlm.nih.gov/ pubmed/28858253

74. Luz CM, Boyles MSP, Falagan-Lotsch P, Pereira MR, Tutumi HR, Oliveira Santos E, et al. Poly-lactic acid nanoparticles (PLA-NP) promote physiological modifications in lung epithelial cells and are internalized by clathrin-coated pits and lipid rafts. J Nanobiotechnol. 2017;15(1):11. Available from: https:// www.ncbi.nlm.nih.gov/pubmed/28143572.

75. Hutter E, Boridy S, Labrecque S, Lalancette-Hebert M, Kriz J, Winnik FM, et al. Microglial response to gold nanoparticles. ACS Nano. 2010;4(5):2595-606. Available from: http://www.ncbi.nlm.nih.gov/pubmed/20329742

76. Soderstjerna E, Bauer P, Cedervall T, Abdshill H, Johansson F, Johansson UE. Silver and gold nanoparticles exposure to in vitro cultured retina--studies on nanoparticle internalization, apoptosis, oxidative stress, glial- and microglial activity. PLoS One. 2014;9(8):e105359. Available from: http:// www.ncbi.nlm.nih.gov/pubmed/25144684

77. Jung S, Bang M, Kim BS, Lee S, Kotov NA, Kim B, et al. Intracellular gold nanoparticles increase neuronal excitability and aggravate seizure activity in the mouse brain. PLoS One. 2014;9(3):e91360. Available from: http://www. ncbi.nlm.nih.gov/pubmed/24625829.

78. Goodman CM, McCusker CD, Yilmaz T, Rotello VM. Toxicity of gold nanoparticles functionalized with cationic and anionic side chains. Bioconjug Chem. 2004;15(4):897-900. Available from: https://www.ncbi.nlm. nih.gov/pubmed/15264879.

79. Lee E, Jeon H, Lee M, Ryu J, Kang C, Kim S, et al. Molecular origin of AuNPsinduced cytotoxicity and mechanistic study. Sci Rep. 2019;9(1):2494. Available from: https://www.ncbi.nlm.nih.gov/pubmed/30792478.

80. Connor EE, Mwamuka J, Gole A, Murphy CJ, Wyatt MD. Gold Nanoparticles Are Taken Up by Human Cells but Do Not Cause Acute Cytotoxicity. Small. 2005; 1(3):325-7. Available from: https://www.ncbi.nlm.nih.gov/pubmed/17193451.

81. Shenoy D, Fu W, Li J, Crasto C, Jones G, DiMarzio C, et al. Surface functionalization of gold nanoparticles using hetero-bifunctional poly (ethylene glycol) spacer for intracellular tracking and delivery. Int J Nanomedicine. 2006;1(1):51-7. Available from: https://www.ncbi.nlm.nih.gov/ pubmed/16467923.

82. Kim D, Park S, Jae HL, Yong YJ, Jon S. Antibiofouling polymer-coated gold nanoparticles as a contrast agent for in vivo $X$-ray computed tomography imaging. J Am Chem Soc. 2007;129(24):7661-5. Available from: https://www. ncbi.nlm.nih.gov/pubmed/17530850.

83. Pamies D, Block K, Lau P, Gribaldo L, Pardo CA, Barreras P, et al. Rotenone exerts developmental neurotoxicity in a human brain spheroid model. Toxicol Appl Pharmacol. 2018;354:101-14. Available from: http://www.ncbi. nlm.nih.gov/pubmed/29428530.

84. Lancaster MA, Renner M, Martin CA, Wenzel D, Bicknell LS, Hurles ME, et al Cerebral organoids model human brain development and microcephaly. Nature. 2013;501(7467):373-9. Available from: http://www.ncbi.nlm.nih.gov/ pubmed/23995685

85. Pasca AM, Sloan SA, Clarke LE, Tian Y, Makinson CD, Huber N, et al. Functional cortical neurons and astrocytes from human pluripotent stem cells in 3D culture. Nat Methods. 2015;12(7):671-8. Available from: http:// www.ncbi.nlm.nih.gov/pubmed/26005811

86. Hillyer JF, Albrecht RM. Gastrointestinal persorption and tissue distribution of differently sized colloidal gold nanoparticles. J Pharm Sci. 2001;90(12): 1927-36. Available from: https://www.ncbi.nlm.nih.gov/pubmed/11745751.

87. Khlebtsov N, Dykman L. Biodistribution and toxicity of engineered gold nanoparticles: a review of in vitro and in vivo studies. Chem Soc Rev. 2011;
40(3):1647-71. Available from: https://www.ncbi.nlm.nih.gov/pubmed/ 21082078.

88. Jain D, Bajaj A, Athawale R, Shrikhande S, Goel PN, Nikam Y, et al. Surfacecoated PLA nanoparticles loaded with temozolomide for improved brain deposition and potential treatment of gliomas: development, characterization and in vivo studies. Drug Deliv. 2016;23(3):999-1016. Available from: https://www.ncbi.nlm.nih.gov/pubmed/25026415.

89. Lundqvist M, Augustsson C, Lilja M, Lundkvist K, Dahlback B, Linse S, et al. The nanoparticle protein corona formed in human blood or human blood fractions. PLoS One. 2017;12(4):e0175871. Available from: http://www.ncbi. nlm.nih.gov/pubmed/28414772

90. Dal Magro R, Albertini B, Beretta S, Rigolio R, Donzelli E, Chiorazzi A, et al. Artificial apolipoprotein corona enables nanoparticle brain targeting. Nanomedicine. 2017;14(2):429-38. Available from: http://www.ncbi.nlm.nih. gov/pubmed/29157979

91. Jenkins SI, Weinberg D, Al-Shakli AF, Fernandes AR, Yiu HHP, Telling ND, et al. "Stealth" nanoparticles evade neural immune cells but also evade major brain cell populations: implications for PEG-based neurotherapeutics. J Control Release. 2016;224:136-45 Available from: http://www.ncbi.nlm.nih. gov/pubmed/26780172.

92. Nance EA, Woodworth GF, Sailor KA, Shih TY, Xu Q, Swaminathan G, et al. A dense poly (ethylene glycol) coating improves penetration of large polymeric nanoparticles within brain tissue. Sci Transl Med. 2012;4(149): 149ra119. Available from: http://www.ncbi.nlm.nih.gov/pubmed/22932224 .

93. Haddad D, Nakamura K. Understanding the susceptibility of dopamine neurons to mitochondrial stressors in Parkinson's disease. FEBS Lett. 2015; 589(24 Pt A):3702-13. Available from: http://www.ncbi.nlm.nih.gov/ pubmed/26526613

94. De Simone U, Caloni F, Gribaldo L, Coccini T. Human co-culture model of neurons and astrocytes to test acute cytotoxicity of neurotoxic compounds. Int J Toxicol. 2017;36(6):463-77. Available from: http://www.ncbi.nlm.nih. gov/pubmed/29153031

95. Umezawa M, Onoda A, Korshunova I, ACØ J, Koponen IK, Jensen KA, et al, Maternal inhalation of carbon black nanoparticles induces neurodevelopmental changes in mouse offspring. Part Fibre Toxicol. 2018.

96. Allen JL, Oberdorster G, Morris-Schaffer K, Wong C, Klocke C, Sobolewski M, et al. Developmental neurotoxicity of inhaled ambient ultrafine particle air pollution: parallels with neuropathological and behavioral features of autism and other neurodevelopmental disorders. Neurotoxicology. 2017.

97. Cui H, Kong $Y$, Zhang H. Oxidative stress, mitochondrial dysfunction, and aging. J Signal Transduct. 2012;2012:646354 Available from: http://www. ncbi.nlm.nih.gov/pubmed/21977319.

98. Haase A, Rott S, Mantion A, Graf P, Plendl J, Thunemann AF, et al. Effects of silver nanoparticles on primary mixed neural cell cultures: uptake, oxidative stress and acute calcium responses. Toxicol Sci. 2012;126(2):457-68. Available from: http://www.ncbi.nlm.nih.gov/pubmed/22240980 .

99. Fard JK, Jafari S, Eghbal MA. A review of molecular mechanisms involved in toxicity of nanoparticles. Adv Pharm Bull. 2015.

100. Choi SS, Lee HJ, Lim I, Satoh J, Kim SU. Human astrocytes: secretome profiles of cytokines and chemokines. PLoS One. 2014;9(4):e92325. Available from: http://www.ncbi.n/m.nih.gov/pubmed/24691121

101. Sun L, He C, Nair L, Yeung J, Egwuagu CE, et al. Interleukin 12 (IL-12) family cytokines: Role in immune pathogenesis and treatment of CNS autoimmune disease. Cytokine. 2015;75(2):249-55. Available from: http:// www.ncbi.nlm.nih.gov/pubmed/25796985 .

102. Rosenstein JM, Krum JM, Ruhrberg C. VEGF in the nervous system. Organogenesis. 2010;6(2):107-14. Available from: http://www.ncbi.nlm.nih. gov/pubmed/20885857

103. Doyle KP, Cekanaviciute E, Mamer LE, Buckwalter MS. TGFbeta signaling in the brain increases with aging and signals to astrocytes and innate immune cells in the weeks after stroke. J Neuroinflammation. 2010;7:62 Available from: http://www.ncbi.n/m.nih.gov/pubmed/20937129.

104. Akdis M, Aab A, Altunbulakli C, Azkur K, Costa RA, Crameri R, et al. Interleukins (from IL-1 to IL-38), interferons, transforming growth factor beta, and TNF-alpha: receptors, functions, and roles in diseases. J Allergy Clin Immunol. 2016;138(4):984-1010. Available from: http://www.ncbi.nlm.nih. gov/pubmed/27577879

105. Kimling J, Maier M, Okenve B, Kotaidis V, Ballot H, Plech A. Turkevich method for gold nanoparticle synthesis revisited. J Phys Chem B. 2006; 110(32):15700-7. Available from: http://www.ncbi.n/m.nih.gov/pubmed/ 16898714. 
106. Schildknecht S, Karreman C, Poltl D, Efremova L, Kullmann C, Gutbier S, et al. Generation of genetically-modified human differentiated cells for toxicological tests and the study of neurodegenerative diseases. ALTEX. 2013;30(4):427-44. Available from: http://www.ncbi.nlm.nih.gov/pubmed/ 24173167.

107. Harris G, Hogberg H, Hartung T, Smirnova L. 3D differentiation of LUHMES cell line to study recovery and delayed neurotoxic effects. Curr Protoc Toxicol. 2017;73:11.23.1-11.23.28. Available from: http://www.ncbi.nlm.nih. gov/pubmed/28777440

108. Wen Z, Nguyen HN, Guo Z, Lalli MA, Wang X, Su Y, et al. Synaptic dysregulation in a human iPS cell model of mental disorders. Nature. 2014 515(7527):414-8. Available from: http:/www.ncbinlm.nih.gov/pubmed/ 25132547.

109. Chomczynski P, Sacchi N. Single-step method of RNA isolation by acid guanidinium thiocyanate-phenol-chloroform extraction. Anal Biochem. 1987; 162(1):156-9. Available from: http://www.ncbi.nlm.nih.gov/pubmed/ 2440339 .

110. Livak KJ, Schmittgen TD. Analysis of relative gene expression data using real-time quantitative PCR and the 2(-Delta Delta $C(T))$ method. Methods. 2001;25(4):402-8. Available from: http://www.ncbi.nlm.nih.gov/pubmed/ 11846609 .

\section{Publisher's Note}

Springer Nature remains neutral with regard to jurisdictional claims in published maps and institutional affiliations.

Ready to submit your research? Choose BMC and benefit from:

- fast, convenient online submission

- thorough peer review by experienced researchers in your field

- rapid publication on acceptance

- support for research data, including large and complex data types

- gold Open Access which fosters wider collaboration and increased citations

- maximum visibility for your research: over $100 \mathrm{M}$ website views per year

At $\mathrm{BMC}$, research is always in progress.

Learn more biomedcentral.com/submissions 